\title{
LEF1/ $\beta$-Catenin Complex Regulates Transcription of the Cav3.1 Calcium Channel Gene (Cacna1g) in Thalamic Neurons of the Adult Brain
}

\author{
Marta B. Wisniewska, ${ }^{1}$ Katarzyna Misztal, ${ }^{1}$ Wojciech Michowski, ${ }^{1,2}$ Marcin Szczot, ${ }^{3}$ Elzbieta Purta, ${ }^{1}$ Wieslawa Lesniak, ${ }^{2}$ \\ Monika E. Klejman, ${ }^{1}$ Michal Dabrowski, ${ }^{2}$ Robert K. Filipkowski, ${ }^{2}$ Andrzej Nagalski, ${ }^{1}$ Jerzy W. Mozrzymas, ${ }^{3}$ and \\ Jacek Kuznicki ${ }^{1,2}$ \\ ${ }^{1}$ International Institute of Molecular and Cell Biology, 02-109 Warsaw, Poland, ${ }^{2}$ Nencki Institute of Experimental Biology, 02-093 Warsaw, Poland, and \\ ${ }^{3}$ Laboratory of Neuroscience, Department of Biophysics, Wroclaw Medical University, 50-367 Wroclaw, Poland
}

$\beta$-Catenin, together with LEF1/TCF transcription factors, activates genes involved in the proliferation and differentiation of neuronal precursor cells. In mature neurons, $\beta$-catenin participates in dendritogenesis and synaptic function as a component of the cadherin cell adhesion complex. However, the transcriptional activity of $\beta$-catenin in these cells remains elusive. In the present study, we found that in the adult mouse brain, $\beta$-catenin and LEF1 accumulate in the nuclei of neurons specifically in the thalamus. The particular electrophysiological properties of thalamic neurons depend on T-type calcium channels. Cav3.1 is the predominant T-type channel subunit in the thalamus, and we hypothesized that the Cacnalg gene encoding Cav3.1 is a target of the LEF1/ $\beta$-catenin complex. We demonstrated that the expression of Cacnalg is high in the thalamus and is further increased in thalamic neurons treated in vitro with LiCl or WNT3A, activators of $\beta$-catenin. Luciferase reporter assays confirmed that the CacnalG promoter is activated by LEF1 and $\beta$-catenin, and footprinting analysis revealed four LEF1 binding sites in the proximal region of this promoter. Chromatin immunoprecipitation demonstrated that the Cacnalg proximal promoter is occupied by $\beta$-catenin in vivo in the thalamus, but not in the hippocampus. Moreover, WNT3A stimulation enhanced T-type current in cultured thalamic neurons. Together, our data indicate that the LEF $1 / \beta$-catenin complex regulates transcription of Cacnalg and uncover a novel function for $\beta$-catenin in mature neurons. We propose that $\beta$-catenin contributes to neuronal excitability not only by a local action at the synapse but also by activating gene expression in thalamic neurons.

\section{Introduction}

LEF1/TCF is a family of transcription factors that recognizes the WWCAAAG motif [also known as Wnt responsive element (WRE)] and is activated by the recruitment of $\beta$-catenin (Hurlstone and Clevers, 2002). Many of the 100 or so known LEF1/TCF targets are involved in cell proliferation and differentiation. Not surprising then is that high levels of LEF1 have been observed in embryonic tissue, lymphocytes (Oosterwegel et al., 1993), and cancer cells (Hovanes et al., 2001; Li et al., 2006; Petropoulos et al., 2008). In the developing mouse brain, LEF1 is implicated in the generation of hippocampal neurons (Galceran et al., 2000).

Received March 25, 2009; revised Feb. 12, 2010; accepted March 1, 2010.

This work was supported by European Union (EU) FP6 Grant "Promemoria” LSHM-CT-2005-512012, Polish Ministry of Science and Higher Education Scientific Network Fund Grant 26/E-40/SN-023/2006, and EU FP7 Grant "Health-Prot" 229676. J.K. and W.M. were partially supported by the Foundation for Polish Science. M.D. was partially supported by a Polish Government Grant 3/0-PBZ-MNil-2/1/2005. M.D. and W.L. were partially supported by statutory funds of the Nencki Institute of Experimental Biology. J.W.M. and M.S. were partially supported by Wroclaw Medical University Basic Research Grant ST-32. We thank Prof. Randall T. Moon, Prof. Rudolf Grosschedl, Prof. RolfKemler, and Dr. Oliver Poetz for providing TOPflash/FOPflash, Lef1, and $\beta$-catenin expression plasmids. We also thank Monika Abramczuk and Dr. Marcin Klejman for help with the experiments and Dr. Lukasz Bojarski and Dr. Anna Skibinska-Kijek for useful discussions.

Correspondence should be addressed to either Marta B. Wisniewska or Jacek Kuznicki, International Institute of Molecular and Cell Biology in Warsaw, 4 Księcia Trojdena Street, 02-109 Warsaw, Poland. E-mail: mwisniew@ iimcb.gov.pl or jkuznicki@iimcb.gov.pl.

DOI:10.1523/JNEUROSCI.1425-09.2010

Copyright $\odot 2010$ the authors $\quad 0270-6474 / 10 / 304957-13 \$ 15.00 / 0$
After birth, Lef1 mRNA levels dramatically decrease in the brain (Coyle-Rink et al., 2002) and can be detected only in the thalamus (Jones and Rubenstein, 2004; Shimogori et al., 2004). The role of LEF1 in the thalamus of the adult brain, however, is unknown.

$\beta$-Catenin is known to function in two cellular compartments (Brembeck et al., 2006). Membranous $\beta$-catenin is involved in cell-cell adhesion via cadherins, whereas in the nucleus it activates LEF1/TCF transcription factors as a mediator of the Wnt signaling pathway. Activation of the Wnt pathway inhibits GSK3 $\beta$ kinase, which is involved in $\beta$-catenin degradation, leading to $\beta$-catenin accumulation and subsequent translocation to the nucleus. Accumulation of this protein occurs in many embryonic and adult self-renewing tissues and in cancer (Clevers, 2006). In the developing and adult brain, $\beta$-catenin is involved in neurogenesis (Chenn and Walsh, 2002; Zechner et al., 2003; Hirabayashi et al., 2004; Lie et al., 2005; Ivaniutsin et al., 2009; Kuwabara et al., 2009). In postmitotic neurons, membranous $\beta$-catenin, together with cadherins, participates in dendritogenesis (Yu and Malenka, 2003; Gao et al., 2007; Peng et al., 2009), synaptogenesis, and synaptic function (Arikkath and Reichardt, 2008 ). Recently, nuclear accumulation of $\beta$-catenin has been described in stimulated hippocampal cells (Chen et al., 2006; Abe and Takeichi, 2007; Schmeisser et al., 2009). However, the question whether $\beta$-catenin plays a role in transcription regulation in mature neurons remains unanswered. This issue is important 
Table 1. Primers used in footprinting

\begin{tabular}{llll}
\hline Template & Location & Forward primer $\left(5^{\prime}-3^{\prime}\right)$ & Reverse primer $\left(5^{\prime}-3^{\prime}\right)$ \\
\hline Hs-CACNA1G & $+27 /+279$ & CTTCGCCGAAGGTAGCGCCGAAT & GGCACATCTGGTGGGCTCTA \\
Hs-CACNA1G & $-137 /+279$ & CCTAAAGAGATCCCTCCTCCC & As above \\
Hs-CACNA1G & $-296 /+97$ & ACAGCTACGGCAGCGGCA & TCACTTTGTCCGGCTTCTTCGCT \\
Mm-Cacna1g & $+139 /+352$ & CTTCACCGAAGGTAGCGCCCATT & AGGAGGGCCAGTTCAGCTCAG \\
Mm-Cacna1g & $-36 /+352$ & CCCAAAGAGATCCCTCCTCC & As above \\
Mm-Cacna1g & $-190 /+61$ & ACAGCTACGGCAACGGCA & TCACTTTGTTCGGCTTCTTCCCT \\
Super8xTOPflash/Super8xFOPflash & - & CTAGCAAAATAGGCTGTCCC (RVPrimer3) & CCTTATGCAGTTGCTCTCC (lucNRev)
\end{tabular}

The primers for the proximal region of the human (Hs) and mouse (Ms) Cacna $1 \mathrm{~g}$ promoter are numbered according to the most upstream transcription start identified experimentally in the human gene (Bertolesi et al., 2003) and predicted in Ensembl in the mouse gene. The primers for the TOP/FOP promoters are identical with the pTA-Luc (vector backbone) sequencing primers.

Table 2. Primers used in the ChIP assay

\begin{tabular}{lcll}
\hline Amplicon & Location & Forward primer $\left(5^{\prime}-3^{\prime}\right)$ & Reverse primer $\left(5^{\prime}-3^{\prime}\right)$ \\
\hline Cacna1g promoter (1) & $+186 /+373$ & AGGGAAGAAGCCGGAACAAAGTGA & TCTAGAGAGCTTGCTGAGCCC \\
Cacna1g promoter (2) & $+37 /+211$ & TTAGATCCTGCTCCAGCTGGGCC & CCCTCACTTTGTTCCGGCTTCTT \\
Cacna1g promoter (3) & $-190 /-16$ & ACAGCTACGGCAACGGCA & GGGAGGAGGGATCTCTTTGGG \\
Cacna1g promoter (4) & $-306 /-225$ & AGGCTTGAAGTTGGAGTGAGGGAT & GCGGAGGGAGAGAACGAGAGAAA \\
Cacna1g promoter (5) & $-473 /-283$ & AGGGTAGAAAGGGGTCGTGGTT & ATCCCTCACTCCAACTTCAAGCCT \\
Cacna1g promoter (6) & $-568 /-450$ & TCCCAAAGACCCAAGAGGCCAATA & AAACCACGACCGCCTTTCTACCCT \\
Cacna1g promoter (7) & TTTAGCTGTGGGATCCCGGTAACA & GAGGAGCCTCGAGAAATCAAAGT \\
Gapdh promoter (P) & $-769 /-578$ & CACCCTGGCATTTTCTTCCA & GACCCAGAGACCTGAATGCTG \\
Gapdh exon (E) & $+284 /+494$ & CAGTGGCAAAGTGGAGATTG & AATTTGCGTGAGTGGAGTC \\
Lef1 promoter (WRE) & $+3074 /+3169$ & CTCGAGCCGGGAACAACAAAGA & GGGGAGAAAAAGAGAGGTTGCC \\
\hline
\end{tabular}

The primers for the Cacna1g promoter, Gapdh promoter and exon, and WRE element in the Lef1 promoter are numbered according to the most upstream transcription start site predicted in Ensembl.

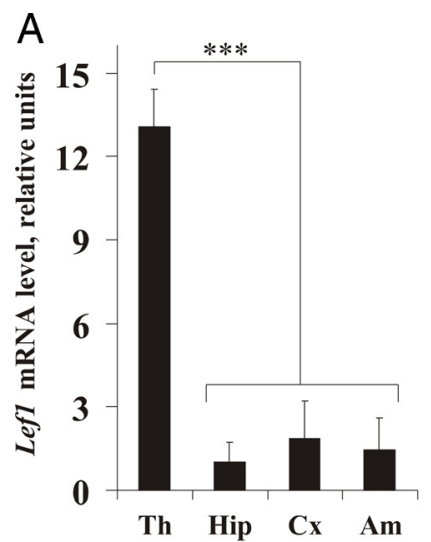

B

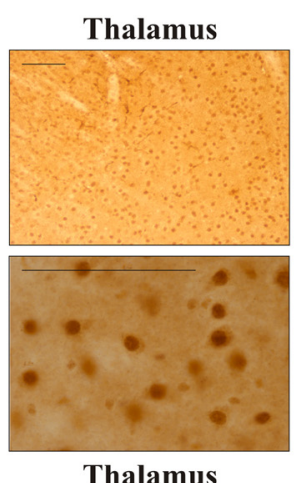

Thalamus

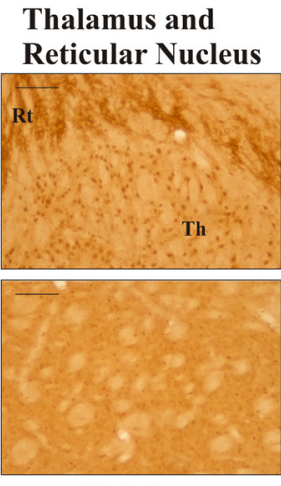

Striatum

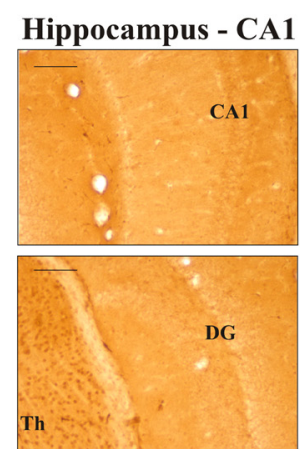

Hippocampus - DG

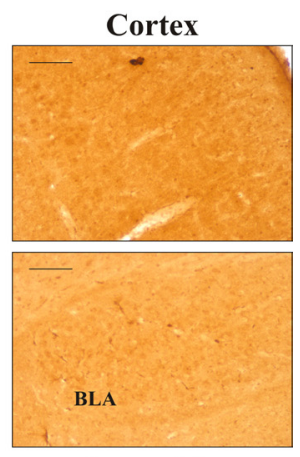

Amygdala

Figure 1. LEF1 distribution in the adult mouse forebrain. $A$, Real-time PCR analysis of Lef1 expression. RNA was obtained from the thalamus, hippocampus, cortex, and amygdala. The Lef1 transcript was detected by real-time PCR with the specific probes. The experiments performed on three female and three male mice gave similar results. All of the results were related to the level of 185 expression. The graph represents results obtained with the male mice. The mean for the hippocampus is set as 1. Error bars indicate SD. ${ }^{* * *} p<0.001$ (two-tailed Student's $t$ test; variable 1 , thalamus; variable 2, hippocampus, cortex, and amygdala). $\boldsymbol{B}$, Immunohistochemical staining for LEF1. The brain sections were labeled with LEF1-specific antibody and stained with the DAB system. Representative sections of one of four brains are shown. Scale bars, $100 \mu \mathrm{m}$. Th, Thalamus; Rt, reticular nucleus; CA1, field CA1; DG, dentate gyrus; BLA, basolateral amygdala.

because Wnt signaling may be implicated in some neurodegenerative and mental disorders (De Ferrari and Moon, 2006; Gould et al., 2007; Mao et al., 2009; Rawal et al., 2009; Sancho et al., 2009).

The present study demonstrates that LEF1 and $\beta$-catenin are both present in neuronal nuclei, specifically in the thalamus. To investigate the role of LEF1/ $\beta$-catenin in adult thalamic neurons, we explored the possible involvement of the complex in the regulation of genes encoding proteins critical for thalamic function. The characteristic property of thalamic neurons is bimodal firing (i.e., tonic and burst), driven by T-type calcium channels (Llinás and Steriade, 2006). Cav3.1 is the predominant T-type channel subunit present in the thalamus (Talley et al., 1999; Kim et al., 2001; Zhang et al., 2002), and we hypothesized that the LEF1/ $\beta$ catenin complex enhances the expression of Cacnalg encoding
Cav3.1 in mature thalamic neurons. We present in silico, in vitro, and in vivo evidence that confirms our hypothesis.

\section{Materials and Methods}

RNA isolation and real-time PCR. Two-month-old male FVB mice were killed by cervical dislocation. Their brains were removed, sectioned, immediately frozen on dry ice, and kept at $-80^{\circ} \mathrm{C}$ until RNA isolation. Thalamic cells cultured in vitro were lysed in RNA Lysis Buffer RLT (QIAGEN) and frozen as described above. RNA was isolated with the RNeasy kit from QIAGEN (RNeasy for Lipid Tissue with additional DNase treatment for brain sections and RNeasy Plus for cells). cDNA was then synthesized (SuperScript III RNase H-Reverse Transcriptase; Invitrogen) and examined by real-time PCR in a 7500 Real-Time PCR System using SYBR Green dye (Applied Biosystems). The results were analyzed by absolute quantification with a relative standard curve. For mouse and rat Cacnalg and rat Cacna1H and Cacna1I transcript detec- 

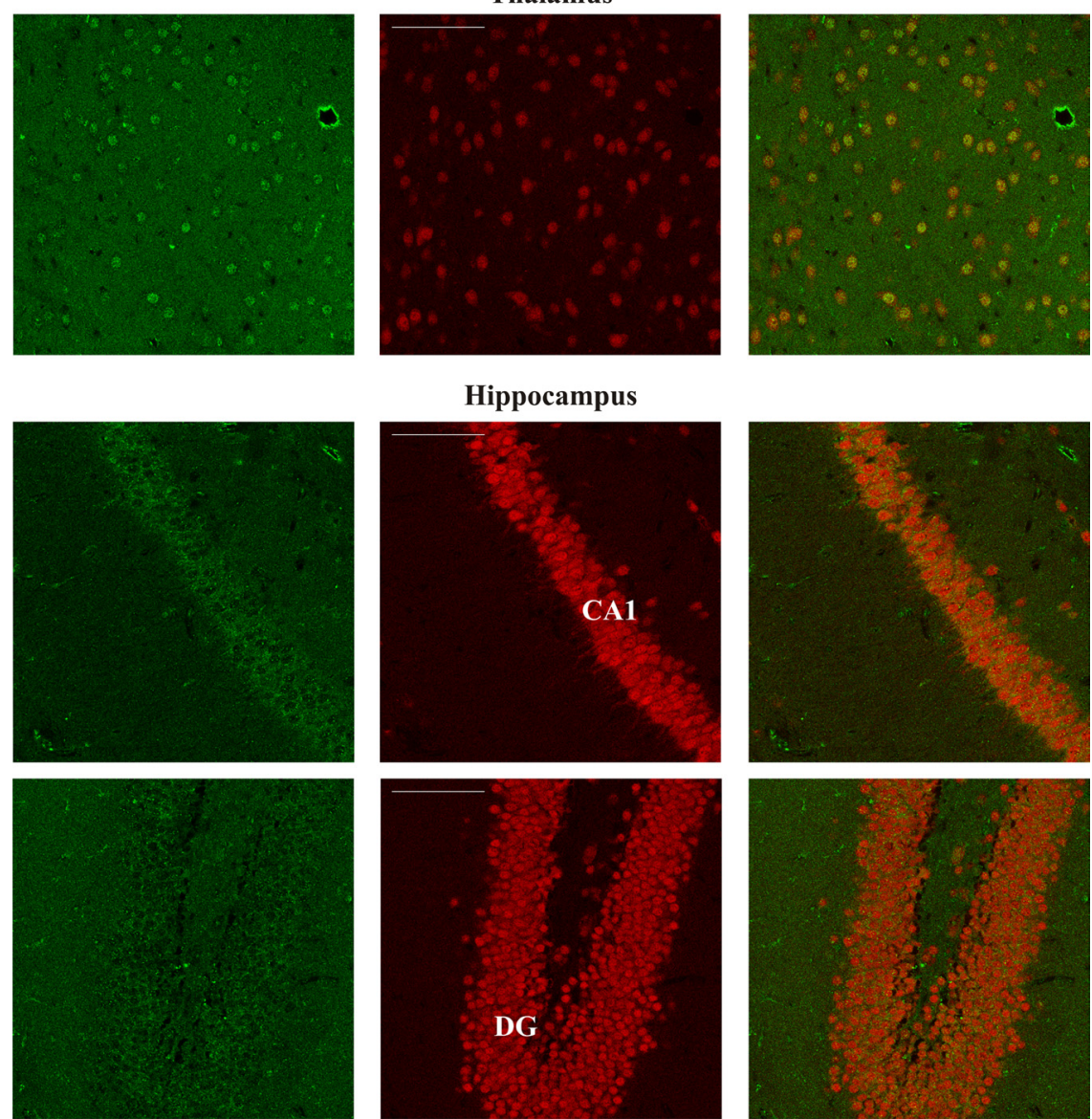

LEF1

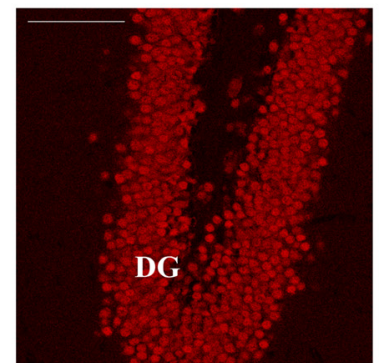

NeuN

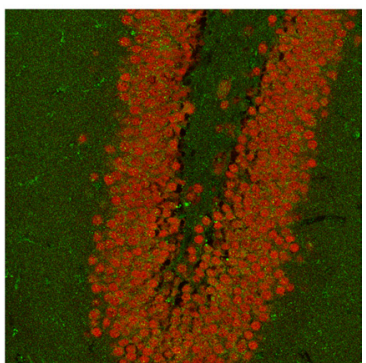

merged

Figure 2. Neuron-specific localization of LEF1 in the adult forebrain. Immunofluorescent staining for LEF1. The brain sections were labeled with LEF1-specific goat polyclonal antibody, neuronal marker NeuN-specific mouse monoclonal antibody, and secondary antibodies coupled with fluorescent dyes. Green fluorescence stains LEF1, and red fluorescence stains NeuN. Representative sections of one of three brains are shown. Scale bars, $100 \mu \mathrm{m}$. CA1, Field CA1; DG, dentate gyrus.

tion, we used commercial pairs of primers (QIAGEN). For mouse Lef1, the primers were identical with those used by others (Nawshad and Hay, 2003), and for $18 \mathrm{~S}$ the primers were the following: forward (F), AACGAACGAGACTCTGGCATG, and reverse (R), CGGACATCTAAGGGCATCACA.

Subcellular fractionation and Western blot. Fresh brain tissues from 2-month-old male or female (where indicated) FVB mice were homogenized in buffer A (10 mM HEPES, pH 7.9, $1.5 \mathrm{~mm} \mathrm{MgCl}_{2}, 10 \mathrm{~mm} \mathrm{KCl,}$ and $0.5 \mathrm{~mm}$ DTT with protease inhibitor mixture from Roche and phosphatase inhibitor mixture from Sigma-Aldrich) using a glass-glass homogenizer and centrifuged at $1000 \times g$ for $10 \mathrm{~min}$. The nuclear fraction pellets were resuspended in buffer $\mathrm{C}$ (20 mM HEPES, pH 7.9, $1.5 \mathrm{~mm}$ $\mathrm{MgCl}_{2}, 0.6 \mathrm{M} \mathrm{KCl}, 0.5 \mathrm{~mm}$ DTT, and $0.2 \mathrm{~mm}$ EDTA with the protease and phosphatase inhibitors) and cleared by centrifugation at $20,000 \times g$ for $30 \mathrm{~min}$. The $1000 \times g$ supernatants were mixed with 0.11 vol of buffer $B$ ( $0.3 \mathrm{M} \mathrm{HEPES}, \mathrm{pH} 7.9,30 \mathrm{~mm} \mathrm{MgCl}_{2}$, and $\left.1.4 \mathrm{M} \mathrm{KCl}\right)$ and centrifuged at $100,000 \times g$ for $1 \mathrm{~h}$. The pellet/membrane fractions were resuspended in buffer M (10 mm Tris, pH 7.4, 1 mm EDTA, 1 mM EGTA, 0.1 M NaCl, $0.5 \%$ Triton X-100, and $0.1 \% \mathrm{NP}-40)$. The $100,000 \times g$ supernatants represented the cytosolic fraction. Protein extracts were separated on $7.5 \%$ SDS-PAGE gel, and $\beta$-catenin was detected by Western blot with anti- $\beta$-catenin antibody (1:500; mouse monoclonal; BD Biosciences Transduction Laboratories). The intensity of the bands was quantified using a GS-800 Calibrated Densitometer and Quantity One software (Bio-Rad).

Immunohistochemistry and fluorescence. Two-month-old male FVB mice were anesthetized and perfused first with $50 \mathrm{ml}$ of ice-cold PBS and then with $50 \mathrm{ml}$ of ice-cold $4 \%$ paraformaldehyde in PBS. The brains were removed and incubated in $4 \%$ paraformaldehyde in PBS for $1-3 \mathrm{~d}$ at $4^{\circ} \mathrm{C}$. Next, the brains were placed in $30 \%$ sucrose until they sank. Brains were then frozen in dry-ice-cold heptane and stored at $-80^{\circ} \mathrm{C}$. The brains were cut into $40 \mu \mathrm{m} \mathrm{sec}-$ tions with a cryostat (Micron; Zeiss). The floating brain sections were washed with PBS (three times; 10 min each time). Endogenous peroxidase was then blocked with $0.3 \% \mathrm{H}_{2} \mathrm{O}_{2}$ in $\mathrm{PBS}$, and the sections were washed again. The sections were incubated for $2 \mathrm{~d}$ at $4^{\circ} \mathrm{C}$ with anti$\beta$-catenin antibody (1:1000; rabbit polyclonal; Santa Cruz) or anti-LEF1 antibody (1:200; goat polyclonal; Santa Cruz) in $0.3 \%$ Triton in PBS with $10 \%$ normal goat or rabbit serum (Vector Laboratories), respectively. After washing, the sections were incubated for $1 \mathrm{~h}$ with biotinylated secondary anti-rabbit or anti-goat antibodies (Vector Laboratories) and then $0.5 \mathrm{~h}$ in Vectastain ABC reagent (Vector Laboratories). Staining was developed with a DAB-based Peroxidase Substrate kit (Vector Laboratories). In the case of double staining with a neuronal marker, the slices were washed after the anti- $\beta$ catenin or anti-LEF1 antibody and incubated with anti-neuronal nuclei (NeuN) antibody (1: 1000; mouse monoclonal; Millipore Bioscience Research Reagents) for $2 \mathrm{~h}$ at room temperature. After three washing steps, the sections were incubated with secondary antibodies (anti-goat or anti-rabbit IgG coupled with Alexa 488 for LEF1 and $\beta$-catenin, respectively, and anti-mouse coupled with Alexa 594 for $\mathrm{NeuN}$; Invitrogen) for $1 \mathrm{~h}$ at room temperature. Photographs were taken under a light or confocal microscope (Leica TCS SP2 OBS).

Primary thalamic culture and cell treatment. Brains removed from embryonic day 19 rat embryos were collected in cold Hanks solution supplemented with $15 \mathrm{~mm}$ HEPES buffer and penicillin/streptomycin. The thalami were isolated, rinsed three times with cold Hanks solution, and trypsinized for 20 min. Then they were rinsed in warm Hanks solution and dissociated by pipetting. Thalamic cells were plated on coverslips coated with poly-Dlysine $(30 \mu \mathrm{g} / \mathrm{ml})$ at a density of 1850 cells $/ \mathrm{mm}^{2}$ in MEM supplemented with $10 \%$ FBS. The next day, the medium was replaced with Neurobasal supplemented with B27 (Invitrogen), $0.5 \mathrm{~mm}$ glutamine, $12.5 \mathrm{~mm}$ glutamate, and penicillin/streptomycin mixed at a 1:1 ratio with cortical neuron conditioned medium. All culture media were purchased from Invitrogen. The neurons were treated with $10 \mathrm{~mm} \mathrm{LiCl}, 0.1 \mu \mathrm{g} / \mathrm{ml}$ WNT3A (mouse recombinant; R\&D Systems), or $0.1 \%$ bovine serum albumin (BSA) in PBS (as a control) for $6 \mathrm{~h}$. The stimulations were performed on day 7 in vitro (DIV7) for gene expression analysis or DIV5-9 for electrophysiological recordings.

Immunocytofluorescent cell staining. Neurons were fixed with ice-cold $4 \%$ paraformaldehyde and 4\% sucrose in PBS for $20 \mathrm{~min}$. The cells were then washed with PBS (three times; 5 min each time) and permeabilized for $10 \mathrm{~min}$ in $0.1 \%$ Triton. To reduce nonspecific binding, the cells were incubated for $30 \mathrm{~min}$ in 5\% BSA. Cells were then incubated for $1.5 \mathrm{~h}$ at room temperature with anti- $\beta$-catenin (1:250; mouse monoclonal; BD Biosciences Transduction Laboratories) and anti-MAP2 (1:100; rabbit polyclonal; Cell Signaling Technology) antibodies in blocking solution (10\% horse serum from Vector Laboratories, 5\% sucrose, and 2\% BSA in PBS). After PBS washings (three times; 5 min each time), the secondary antibodies (anti-mouse IgG coupled with Alexa 594 and anti-rabbit coupled with Alexa 488; Invitrogen) were applied in the blocking solution for $45 \mathrm{~min}$ at room temperature. Finally, the cells were washed again in PBS 
(three times; 5 min each time), and coverslips were mounted on slides with Moviol and analyzed under an epifluorescent microscope (Eclipse 80i; Nikon).

In silico promoter analysis. Putative cisregulatory regions in the human and mouse Cacnalg promoter regions were identified on the basis of sequence conservation between -5000 and +2000 (Ensembl numeration) from the transcription start site (TSS) with AVID-VISTA programs (Bray et al., 2003; Frazer et al., 2004) with the default parameters. Potential LEF1/TCF binding motifs (described by matrix family V\$LEFF) were identified using MatInspector (Genomatix) with the default (optimized) threshold.

Cloning and mutation of the human and mouse Cacnalg promoter. The human CACNA1G $1.1 \mathrm{~kb}$ promoter region was amplified on the template of EcoRI-digested total human DNA with the following pair of primers: F, ACCAGGTGGAGACCTGGGATTT, and R, TCAGAGGAGGTGTCCTCACGCAA.

Because of the high amount of nonspecific products, the second PCR program was run using $1 \mu$ l of the first reaction as a template and the following pair of internal primers: BglII-F, GAAGATCTTCCGGCTGCTGCCCAAATCAG, and HindIII-R, CCCAAGCTTCTCAGAGGAGGTGTCCTCACG.

The PCR programs were performed with KAPA2G Robust proofreading DNA polymerase (KAPA Biosystems). The cycling conditions (35 cycles) consisted of denaturation at $98^{\circ} \mathrm{C}$ for $15 \mathrm{~s}$, annealing for $30 \mathrm{~s}$, and extension at $72^{\circ} \mathrm{C}$ for $2 \mathrm{~min}$. The annealing temperatures in the first, second, and third cycle were 63,60 , and $57^{\circ} \mathrm{C}$, respectively, and $54^{\circ} \mathrm{C}$ for the remaining cycles. The BglII- and HindIII (Fermentas)-digested product was ligated with the digested pTA-Luc plasmid (Clontech) using T4 DNA Ligase (Fermentas). Digestion of pTA-Luc with BglII and HindIII resulted in the loss of the minimal TA promoter, so the only transcription driving elements in the final plasmid were those from the CACNA1G promoter.

The mouse Cacnalg promoter was cloned similarly to the human one. The $1.3 \mathrm{~kb}$ fragment was amplified from total mouse DNA with the following pair of primers: F, TGAGAAGACCTGCGGGTTGGG, and R, GGTGTCCTCACACAACCGGGG. The fragment was used as a template for the following pair of internal primers: NheI-F, ATCAAGCTAGCCCAGACCACGCCTACTTCTACCTTTC, and HindIII-R, ATCAAAGCTTGGGGGGCTCTAGAGAGCTTGCTG.

Generation of the human promoter deletion fragments (see Fig. $7 C)-680 /+259 \mathrm{AB},-680 /+83 \mathrm{~A},+7 /+259 \mathrm{~B}$, and $+76 /+259 \mathrm{~B}$ was achieved by PCR using primers identical with those used by others (Bertolesi et al., 2003), namely F23/R962, F23/R790, F708/R962, and F778/R962, respectively. The $-680 \mathrm{~A} /+8 \mathrm{~A}$ fragment was amplified with F23 and a new primer R727, GCCTCGAGCGAAAAGGGGGGCA. The PCR cycles used here were the same as for the amplification of the initial $C A C N A 1 G$ promoter. All of the deletion mutants of the CACNA1G promoter were cloned into the pTA-Luc with the previously deleted minimal TA promoter sequence.

The putative LEF1 binding site in the CACNA1G promoter was mutated (AACAAAG into GCCAAAG) by PCR with Pfu ULTRA HF polymerase (Stratagene) using the following pair of primers: Mut-F, CCAAAGTGAGGGGGAGCCGGC, and Mut-R, CCCGGCTTCTTCGCTTCGCG. PCR was performed under 25 cycles at $95^{\circ} \mathrm{C}$ for $30 \mathrm{~s}, 55^{\circ} \mathrm{C}$ for $30 \mathrm{~s}$, and $72^{\circ} \mathrm{C}$ for $12 \mathrm{~min}$. The entire reaction was treated with DpnI restrictase (Fermentas) to get rid of the original plasmid. The product

\section{Thalamus and} Reticular Nucleus
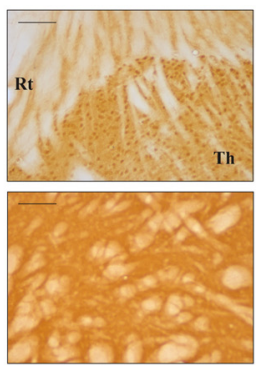

Striatum

C
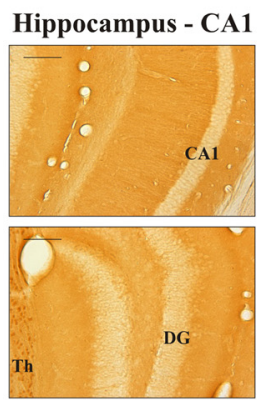

Hippocampus - DG
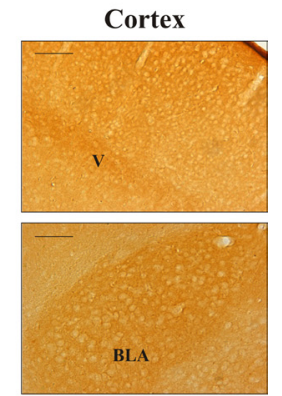

Amygdala
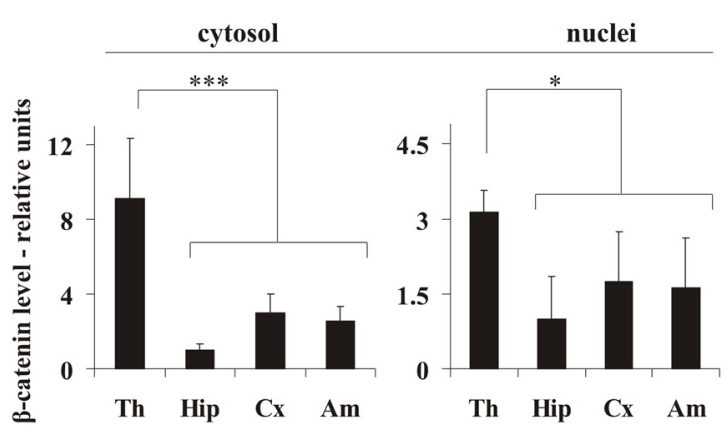

Figure 3. $\beta$-Catenin distribution in the adult mouse forebrain. $\boldsymbol{A}$, Immunohistochemical staining for $\beta$-catenin. The brain sections were labeled with $\beta$-catenin-specific antibody and stained with the DAB system. Representative sections of one of eight

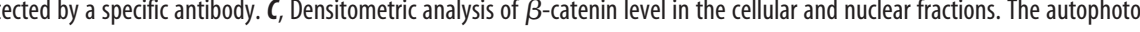
列

was next phosphorylated with T4 polynucleotide kinase (Fermentas) and ligated with T4 DNA Ligase (Fermentas).

The correctness of the cloned promoter fragments and the substitution of specific nucleotides were confirmed by sequencing.

HeLa cell transfection, vectors, and luciferase assay. HeLa cells were purchased from American Type Culture Collection and cultured according to the manufacturer's instructions. A total of $2 \times 10^{4}$ cells was seeded in each well of a 24 -well plate $1 \mathrm{~d}$ before transfection. Transfection was performed with $0.05 \mu \mathrm{g}$ of control pRL-TK vector with the Renilla luciferase gene (Promega), $0.25 \mu \mathrm{g}$ of reporter plasmid with firefly luciferase together with $0.5 \mu \mathrm{g}$ of pCG vector or $0.25 \mu \mathrm{g}$ of mouse LEF1 (a kind gift from Prof. Rudolf Grosschedl, Max Planck Institute of Immunobiology, Freiburg, Germany), and $0.25 \mu \mathrm{g}$ of mouse $\beta$-catenin [a kind gift from Prof. Rolf Kemler (Max Planck Institute of Immunobiology) and Dr. Oliver Poetz (Natural and Medical Sciences Institute at University of Tuebingen, Reutlingen, Germany)] expression CMV plasmids per well. We used the following reporter plasmids: the human CACNA1G and mouse Cacnalg promoter constructs Super8xTOPflash (TOP) and Super8xFOPflash (FOP) (Veeman et al., 2003), and pTAluc (Clontech). TOP and FOP plasmids were obtained from Addgene. Twenty microliters of OPTI-MEM medium (Invitrogen) and $2 \mu \mathrm{l}$ of $1 \mathrm{mg} / \mathrm{ml} \mathrm{PEI} \mathrm{(polyethyleni-}$ mine) were added to the DNA, vortexed, and incubated for $15 \mathrm{~min}$ at room temperature. The mixture was then diluted with $120 \mu \mathrm{l}$ of complete medium and added to the cells. The cells were collected $48 \mathrm{~h}$ after transfection. The luciferase assay was performed using the Dual Luciferase Assay System (Promega) and a TD 20/20 luminometer (Turner BioSystems).

LEF1 purification and footprinting. Mouse Lef1 was subcloned into a pET28a(+) vector, in-frame with the $C$-terminal His Tag. The Lef1 fragment was obtained by PCR using the following pair of primers: NcoI-F, 

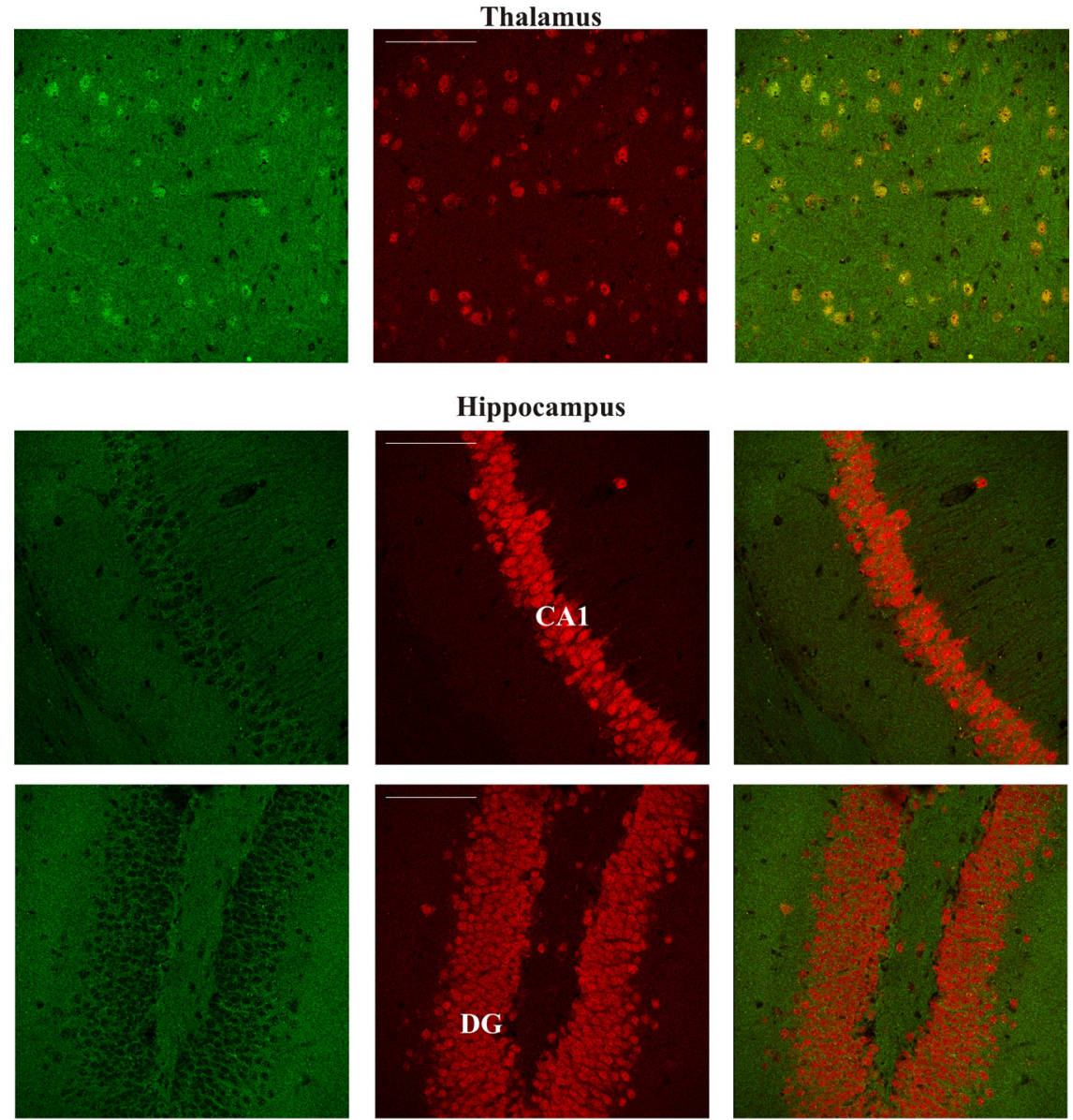

$\beta$-catenin

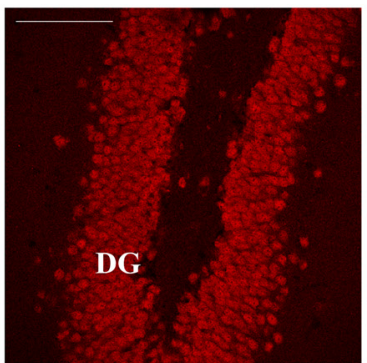

NeuN

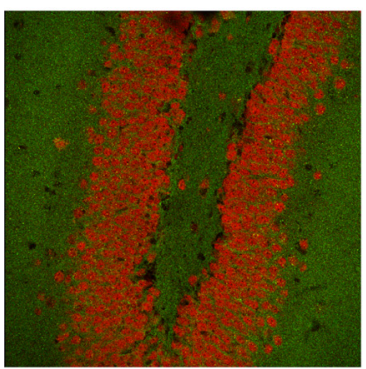

merged

Figure 4. Neuron-specific localization of $\beta$-catenin in the adult forebrain. Immunofluorescent staining for $\beta$-catenin. The brain sections were labeled with $\beta$-catenin-specific rabbit polyclonal antibody, neuronal marker NeuN-specific mouse monoclonal antibody, and secondary antibodies coupled with fluorescent dyes. Green fluorescence stains $\beta$-catenin, and red fluorescence stains NeuN. Representative sections of one of three brains are shown. Scale bars, $100 \mu \mathrm{m}$. CA1, Field CA; DG, dentate gyrus.

\section{CGCCATGGCTCATATGCCCCAACTTTCC, and HindIII-R, CGAAG- CTTGGCTGTCATTCTGGGACC.}

The LEF1 protein was purified as described by others (Tutter et al., 2001), with minor modifications. Protein expression was induced in $0.5 \mathrm{~L}$ of BL21 Rosetta Escherichia coli culture by IPTG (isopropyl $\beta$-Dthiogalactoside) ( $2 \mathrm{~mm}$ for $2 \mathrm{~h}$ at $\left.37^{\circ} \mathrm{C}\right)$. The bacteria were resuspended in $8 \mathrm{ml}$ of lysis buffer (PBS with $0.25 \mathrm{M} \mathrm{NaCl}$ final concentration, $1 \%$ Triton $\mathrm{X}-100,10 \mathrm{~mm}$ imidazole, $1 \mathrm{~mm}$ DTT, $1 \mu \mathrm{g} / \mathrm{ml}$ DNase I, $0.1 \mathrm{mg} / \mathrm{ml}$ lysozyme, and protease inhibitors from Roche) and lysed using French press. The supernatant obtained after ultracentrifugation was incubated with $4 \mathrm{ml}$ of Ni-NTA (nickel-nitrilotriacetate) agarose (QIAGEN). After extensive washing with HG buffer (20 mM HEPES, pH 7.4, 10\% glycerol, and $0.1 \mathrm{M} \mathrm{KCl}$ ), the bound fraction was eluted in elution buffer (HG with $0.3 \mathrm{~m}$ imidazole, $1 \mathrm{~mm}$ DTT, and protease inhibitors). The protein was further purified on MonoQ equilibrated with HEG buffer (HG with 0.1 mM EDTA) using 0.1-0.5 $\mathrm{M} \mathrm{KCl} \mathrm{linear} \mathrm{gradient.} \mathrm{The} \mathrm{purified} \mathrm{LEF1} \mathrm{was}$ dialyzed against HEG buffer with 1 mM DTT, concentrated on Vivaspin $10000 \mathrm{MWCO}$ centrifuge concentrators (Sartorius), and frozen at $-80^{\circ} \mathrm{C}$ in small aliquots.

To obtain the human and mouse Cacnalg promoter probes, we used the primers that are listed in Table 1 . The forward primers were single end-labeled on the $5^{\prime}$ end with $\left[\gamma_{-}{ }^{33} \mathrm{P}\right] \mathrm{ATP}$ using T4 polynucleotide kinase (Fermentas) followed by the purification step on Mini Quick Spin Columns (Roche). The PCR products were gel-purified with the QIAEX II Gel Extraction kit (QIAGEN). The recombinant LEF1 $(1 \mu \mathrm{g})$ was incubated with 10-20 fmol of the labeled DNA for 20 min on ice in $50 \mu \mathrm{l}$ of binding buffer (50 mM Tris, pH 7.9, 12.5 mM $\mathrm{MgCl}_{2}, 1$ mм EDTA, 20\% glycerol, $0.1 \% \mathrm{NP}-40$, and $50 \mathrm{~mm} \mathrm{KCl}$ ) as described by others (Hovanes et al., 2000). Fifty microliters of cofactor solution was then added (10 $\mathrm{mm} \mathrm{MgCl}_{2}, 5 \mathrm{~mm} \mathrm{CaCl}_{2}$ ), and the samples were treated with $0.05 \mathrm{U}$ of DNase for $90 \mathrm{~s}$ at room temperature. The reaction was stopped with $0.1 \mathrm{ml}$ of stop solution (1\% SDS, $0.2 \mathrm{M}$ $\mathrm{KCl}, 20 \mathrm{~mm}$ EDTA, $\mathrm{pH}$ 8.0, and $50 \mathrm{ng} / \mu \mathrm{l}$ glycogen), and DNA was recovered by standard phenol-chloroform extraction and ethanol precipitation. In parallel, $\mathrm{G}+\mathrm{A}$ chemical sequencing was performed (Maxam and Gilbert, 1980). The samples were resuspended in $4.5 \mu \mathrm{l}$ of gel loading buffer $(7 \mathrm{~m}$ urea, $0.1 \times \mathrm{TBE}$ buffer, $0.05 \%$ xylene cyanole, and bromophenol blue) and resolved on 6 or $10 \%$ denaturating polyacrylamide gel.

Chromatin immunoprecipitation. One- to 4-month-old male FVB mice were killed by cervical dislocation, and the brains were removed and sectioned. Two thalami and four hippocampi were disrupted using a glass-glass homogenizer in $5 \mathrm{ml}$ of PBS with protein inhibitors (Roche). A volume of $0.5 \mathrm{ml}$ of $11 \%$ formaldehyde in $0.1 \mathrm{M} \mathrm{NaCl}, 1 \mathrm{~mm}$ EDTA, and 50 mм HEPES, pH 8.0, was then added. After $40 \mathrm{~min}$ incubation at room temperature, 250 $\mu \mathrm{l}$ of $2.5 \mathrm{~m}$ glycine was added to quench the formaldehyde. The cells were spun down and rinsed twice with $10 \mathrm{ml}$ of $\mathrm{PBS}$ at $4^{\circ} \mathrm{C}$, and the pellet was frozen at $-80^{\circ} \mathrm{C}$. The material was thawed on ice, resuspended in $0.2 \mathrm{ml}$ of lysis buffer (1\% SDS, $10 \mathrm{~mm}$ EDTA, and $50 \mathrm{~mm}$ Tris-HCl, pH 8.0, supplemented with the protease inhibitors), and sonicated on ice four times for $20 \mathrm{~s}$ each time with $40 \mathrm{~s}$ breaks at a $50 \%$ duty cycle and $50 \%$ power using a Sonopuls Bandeline sonicator. This treatment yielded an average of 700-1000 bp DNA fragments. Samples were centrifuged at 15,000 $\times g$ for $10 \mathrm{~min}$, and their DNA content was measured spectrophotometrically. Sixty micrograms of DNA per sample were used for the subsequent immunoprecipitation procedure performed with $10 \mu \mathrm{g}$ of anti-rabbit IgG antibody (Sigma-Aldrich), $10 \mu \mathrm{g}$ of anti-acetyl-histone H3 (rabbit polyclonal; Millipore), and $40 \mu \mathrm{g}$ of anti- $\beta$-catenin antibody (rabbit polyclonal; Santa Cruz). The chromatin immunoprecipitation (ChIP) assay was conducted according to the Millipore protocol using salmon sperm DNA protein A-agarose (Millipore). Spin-X centrifuge tube filters $(0.45 \mu \mathrm{m}$; Corning Life Sciences) were used during the washing procedure. Immunoprecipitated DNA was used as a template in the real-time PCR assay. The primers used in the ChIP assay are listed in Table 2. The results were calculated using the $\Delta \Delta C t$ method and reported as fold enrichment above background (rabbit IgG).

Electrophysiological recording and analysis. The thalamic cells cultures were treated as described above with WNT3A (mouse recombinant; R\&D Systems) for $6 \mathrm{~h}$. Calcium currents were recorded in the whole-cell mode of the patch-clamp technique 2-3 d after stimulation using an Axopatch 200B amplifier (Molecular Devices) and pClamp 10 acquisition software (Molecular Devices). Patch pipettes were pulled with a two-step puller (Narishige PP-83) from glass capillaries (Hilgenberg). The pipette solution contained $125 \mathrm{~mm} \mathrm{CsCl}, 10 \mathrm{~mm}$ tetraethylammonium chloride (TEA-Cl), $10 \mathrm{~mm}$ HEPES, $10 \mathrm{~mm}$ D-glucose, $5 \mathrm{~mm}$ EGTA, $4 \mathrm{~mm} \mathrm{Na}_{2} \mathrm{ATP}$, and $1 \mathrm{~mm} \mathrm{MgCl}_{2}, \mathrm{pH} 7.4$ (adjusted with $\mathrm{CsOH}$ ), 310-315 osmol with sucrose. The patch pipettes had resistance (when filled with pipette solution) in the range of 2.5-4.5 M 2 . The series resistance was monitored, and the cells exhibiting resistances $>15 \mathrm{M} \Omega$ were excluded from the analysis. In these conditions, series resistance compensation did not alter either the current amplitudes or the time course. The bath 
solution contained $125 \mathrm{~mm} \mathrm{NaCl}, 20 \mathrm{~mm}$ HEPES, $10 \mathrm{~mm}$ TEA-Cl, $10 \mathrm{~mm}$ D-glucose, 10 $\mathrm{mM} \mathrm{CaCl}, 1 \mathrm{mM} \mathrm{MgCl}_{2}$, and $1 \mu \mathrm{M}$ tetrodotoxin, $\mathrm{pH} 7.4$ (adjusted with $\mathrm{NaOH}$ ), 335-340 osmol with sucrose.

Calcium current-voltage relationships were assessed by applying $200 \mathrm{~ms}$ depolarizing voltage steps from a holding potential of $-90 \mathrm{mV}$ (or more negative in the case of steady-state inactivation or tail current recordings) to potentials ranging from -50 to $-30 \mathrm{mV}$. In this voltage range, calcium current is mediated mainly by low-voltage-activated T-type calcium channels. Currents evoked by depolarization to voltages above $-30 \mathrm{mV}$ were not analyzed because of contamination from high-voltage-activated calcium channel activity that, in our experiments, was not possible to subtract from currents mediated by T-type channels.

Steady-state inactivation was determined using the standard protocol in which a depolarizing pulse to $-30 \mathrm{mV}$ was applied from different holding potentials ranging from -120 to $-50 \mathrm{mV}$. The steady-state inactivation curve was fitted with Boltzmann's equation as follows:

$$
\frac{I}{I_{\mathrm{MAX}}}=\frac{1}{1+\exp \left(\frac{V_{\mathrm{MID}}-V}{V_{c}}\right)},
$$

where $I_{\mathrm{MAX}}$ is the maximum current elicited from a holding potential of $-120 \mathrm{mV}$ (presumably no inactivation), $V_{\mathrm{MID}}$ is the voltage at which $50 \%$ of channels are inactivated, and $V_{c}$ is the fitting parameter related to the steepness of the sigmoidal relationship.

To measure the tail currents, cells where depolarized from a holding potential of -120 to $-30 \mathrm{mV}$ for $10 \mathrm{~ms}$ and then repolarized to potentials ranging from -120 to $-60 \mathrm{mV}$. The time course of tail current decay (deactivation kinetics) was described by fitting the single exponential function $y(t)=$ $A \exp \left(-t / \tau_{\text {DEAC }}\right)$, where $\tau_{\text {DEAC }}$ is the deactivation time constant. Similarly, the inactivation kinetics (current fading during a prolonged depolarization) was described by fitting with a single exponential function with the time constant $\left(\tau_{\text {DEAC }}\right)$.

In all protocols, a standard $\mathrm{P} / 4$ procedure was used for leak subtraction. Data were analyzed with Clampfit 10 software (Molecular Devices). Cell capacitance was assessed with a pClamp 10 membrane test routine. Current amplitudes were normalized to cell capacitance to compensate for variability attributable to cell size. All experiments were performed at room temperature.

\section{Results}

LEF1 level in the adult brain is high only in thalamic neurons Lef1 mRNA has been shown by in situ hybridization to be expressed in the thalamus of the adult mouse brain (Shimogori et al., 2004). To obtain quantitative and comparative data about Lef1 expression, we performed real-time PCR analysis of mRNA from different regions of the mouse brain: thalamus, hippocampus, cortex, and amygdala. We found that the expression of Lef1 is $\sim 10$-fold higher in the thalamus than in any other region of the forebrain (Fig. 1A).

We next stained the adult brain sections with an antibody against LEF1 to determine whether the LEF1 protein was also specifically elevated in the thalamus and in what types of cells.

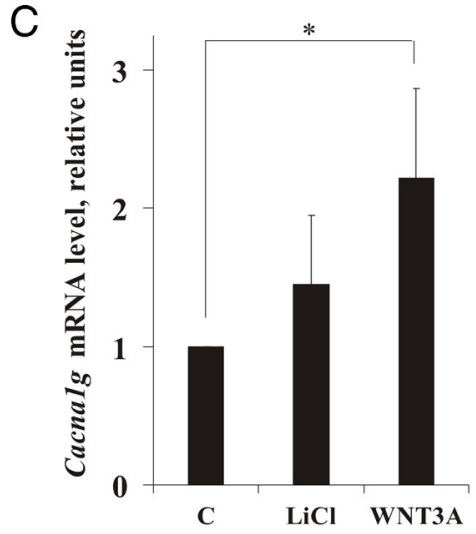

Th Hip Cx Am

$\mathrm{LiCl}$
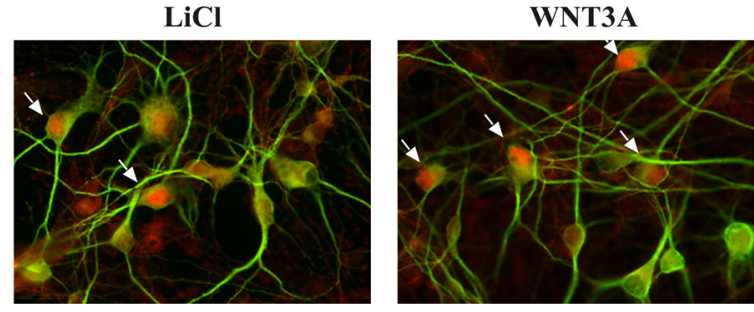

Figure 5. Expression of Cacna1g in the forebrain and thalamic neurons in vitro. $\boldsymbol{A}$, Real-time $P C R$ analysis of Cacna $1 g$ expression in the forebrain. RNA was obtained from the thalamus, hippocampus, cortex, and amygdala. The Cacna $g$ transcript was detected

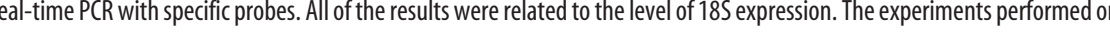
the hippocampus is set as 1. Error bars indicate SD. ${ }^{* * *} p<0.001$ (two-tailed Student's $t$ test; variable 1, thalamus; variable 2 hippocampus, cortex, and amygdala). Th, Thalamus; Hip, hippocampus; (Xx, cortex; Am, amygdala. B, Immunofluorescence analCossion in thalamic neurons in vitro treated with LiCl and WNT3A. RNA was obtained from control thalamic cells and 保 were related to the level of $18 \mathrm{~S}$ expression. The graph represents the mean of five independent experiments. The control is set as 1. Error bars indicate SD. $p=0.115,{ }^{*} p=0.013$, for LiCl and WNT3A treatment, respectively (two-tailed Student's $t$ test).

Many immunopositive cells were observed in the thalamus (also called the dorsal thalamus), but not in the other forebrain regions (Fig. $1 B$ ). The staining was limited to the nuclei of the cells. In the hindbrain, the cerebellar Purkinje layer was also stained, but the staining was weaker than in the thalamus (supplemental Fig. $1 \mathrm{~A}$, available at www.jneurosci.org as supplemental material). We next costained the forebrain sections with an antibody against NeuN neuronal marker and found that LEF1-positive cells in the thalamus were also NeuN-positive (Fig. 2). The results showed that, in the brain, the LEF1 transcription factor is expressed at a high level specifically in thalamic neurons. The transcriptional activity of LEF1 depends on the interaction with its inducible cofactor, $\beta$-catenin, and our next step was to examine the level and distribution of $\beta$-catenin in the adult brain.

Nuclear $\boldsymbol{\beta}$-catenin is present specifically in thalamic neurons To analyze the distribution of $\beta$-catenin in the adult mouse brain, we stained the sections with a $\beta$-catenin-specific antibody. Although a strong neuropilar signal, suggesting membranous localization of the protein, was observed everywhere in the brain (Fig. $3 A$ ), intense intracellular staining was detected only in the thalamus (dorsal thalamus) (Fig. $3 A$ ). $\beta$-Catenin intracellular staining was also seen in some Purkinje cells (supplemental Fig. $1 B$, available at www.jneurosci.org as supplemental material), although 
A
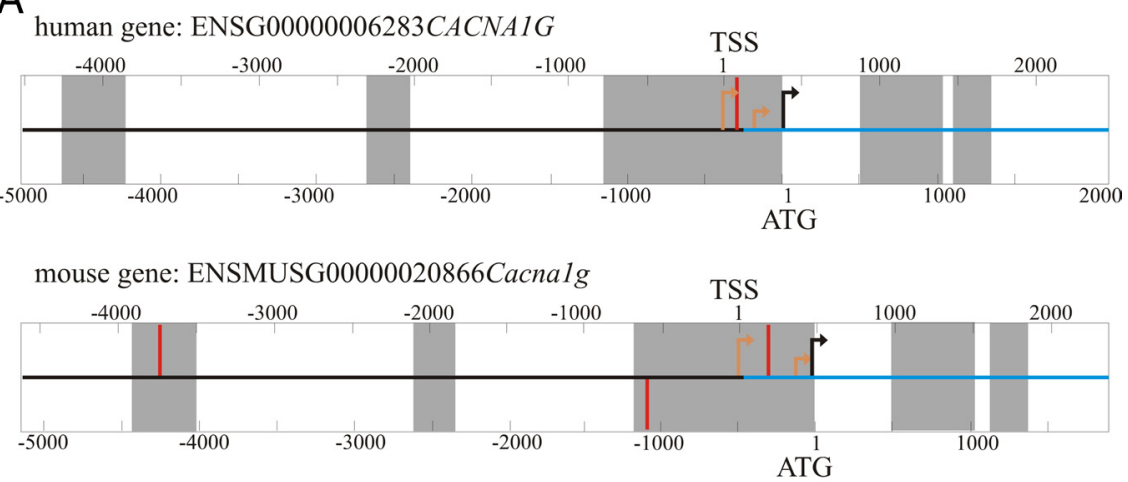

B
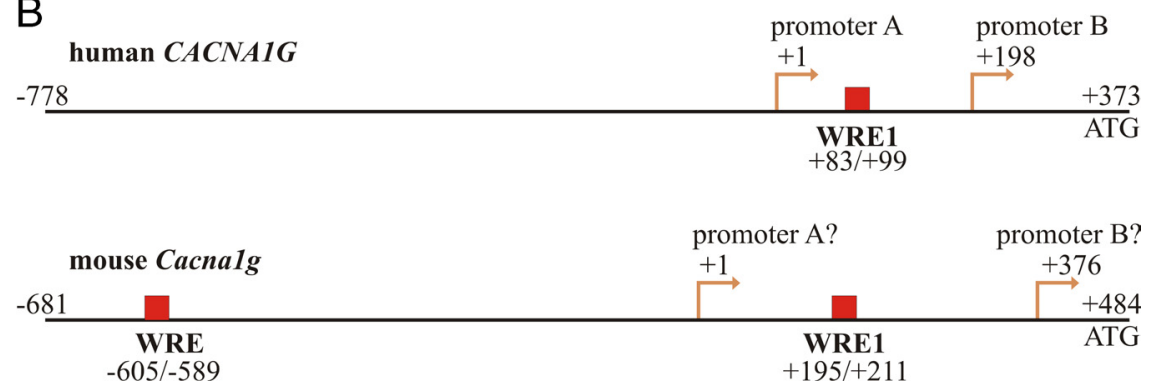

Figure 6. Comparative in silico analysis of the human and mouse Cacna $1 g$ promoter. $A$, Graphic representations of the human and mouse Cacna1g promoter regions $(-5000 /+2000$ bp). Putative cis-regulatory regions (conserved noncoding regions), identified on the basis of sequence conservation, are marked as gray blocks. LEF1/TCF binding motifs are marked as red bars. Cyan lines mark coding regions. Orange arrows mark the two alternative TSSs identified experimentally in human (Bertolesi et al., 2003) and predicted in mouse (Ensembl). The black arrows mark the translation start sites. Nucleotide positions relative to the ATG and most upstream TSS are shown. $\boldsymbol{B}$, Graphic representations of the proximal conserved region in the human and mouse Cacna1g promoter. The A and B TSSs in the human promoter and the predicted (Ensembl) TSS in the mouse promoter are indicated. The putative LEF1 binding sites are represented by red squares.

the staining was weaker than in thalamic cells. To confirm the specificity of $\beta$-catenin accumulation in the thalamus, we examined by Western blot the subcellular fractions isolated from different parts of the forebrain. The cytosolic and nuclear fractions of the thalamus contained more $\beta$-catenin than the same fractions from other parts of the forebrain (Fig. $3 B$ ). Densitometric analysis of the results showed that the level of nuclear $\beta$-catenin was $\sim 2$ - to 3 -fold higher and that of cytosolic $\beta$-catenin was 3 - to 10 -fold higher in the thalamus than in the hippocampus, cortex, or amygdala (Fig. 3C). As expected, similar amounts of $\beta$-catenin were detected in the membranous fractions of different parts of the forebrain, confirming the existence of a membranous pool of $\beta$-catenin in all of these brain regions.

We next determined whether nuclear $\beta$-catenin was present in neuronal cells. As performed for LEF1, the brain sections stained with the anti- $\beta$-catenin antibody were costained with anti-NeuN antibody. This allowed us to identify thalamic $\beta$-catenin-positive cells as neurons (Fig. 4). We concluded that both the LEF1 transcription factor and $\beta$-catenin are present in thalamic neurons, implying their involvement in the regulation of gene transcription in the thalamus.

Expression of Cacnalg is high in the thalamus and elevated in $\mathrm{LiCl}$ - and WNT3A-treated thalamic neurons in vitro

The distribution of LEF1 protein and nuclear $\beta$-catenin in the forebrain strikingly resembled the pattern of Cacnalg expression visualized by hybridization in situ (Talley et al., 1999; Zhang et al., 2002). We hypothesized that LEF1/ $\beta$-catenin may be implicated in Cacnalg expression.
We further investigated the relationship between nuclear $\beta$-catenin localization and Cacnalg expression in neurons. First, relative levels of Cacnalg mRNA in the thalamus, hippocampus, cortex, and amygdala were estimated using real-time PCR. We found that Cacnalg expression was 5 - to 10 -fold higher in the thalamus than in other regions of the forebrain (Fig. 5A). This correlated well with the presence of LEF1 (Fig. 1) and nuclear $\beta$-catenin in the thalamus (Fig. 3). We next examined the expression of Cacnalg mRNA in thalamic primary cultures treated with $\mathrm{LiCl}$, a GSK3 $\beta$ inhibitor, and those treated with WNT3A. Both treatments led to a strong accumulation of $\beta$-catenin in the nuclei (Fig. $5 B$ ) and an increase in nuclear $\beta$-catenin-positive cells (control, 28\%, $n=$ 229; LiCl-treated cells, $49 \%, n=246$; WNT3A-stimulated cells, $47 \%, n=280$ ). Real-time PCR analysis revealed that $\mathrm{LiCl}$ treatment enhanced the expression of Cacnalg $\sim 1.5$-fold and WNT3A $>2$-fold in thalamic cells (Fig. 5C). In parallel, we examined the expression of CacnalH and Cacna1I, which encode alternative subunits of T-type calcium channels. We found that CacnalH and CacnalI expression was not affected by WNT3A $(1.15 \pm 0.46$ - and $1.16 \pm 0.38$-fold activation for Cacna1H and CacnalI, respectively; $n=6$ ), indicating that the increase in the level of Cacnalg expression was specific. These results support the hypothesis that Cacnalg is a target of LEF $1 / \beta$-catenin.

\section{Human and mouse Cacnalg gene promoters have LEF1 motifs in conserved regions}

To further support our hypothesis that the Cacnalg promoter could be a target of LEF1/ $\beta$-catenin, we searched for LEF1 binding sites (i.e., WREs) in silico, in the DNA fragments $5 \mathrm{~kb}$ upstream and $2 \mathrm{~kb}$ downstream from the TSS of the human and mouse Cacnalg (Fig. 6A). The analysis demonstrated several conserved regions between the human and mouse Cacnalg loci, which are likely regulatory elements. We found three putative LEF1 binding sites within the presumed regulatory elements in the mouse locus, one of which was conserved in the human gene. This putative LEF1 binding site was located in the mouse promoter between nucleotides +195 and +211 from the TSS (the most upstream predicted TSS; Ensembl) (Fig. 6B). In the human promoter, the site was placed between the experimentally identified $\mathrm{A}(+1)$ and $\mathrm{B}(+198)$ alternative TSSs (Bertolesi et al., 2003). Thus, Cacnal $g$ could be directly regulated by the LEF1/ $\beta$-catenin complex.

\section{Human and mouse Cacnalg promoter is activated by the LEF1/ $\beta$-catenin complex}

To determine whether the Cacnalg promoter is in fact regulated by the LEF1/ $\beta$-catenin complex, we analyzed the activity of the human and mouse promoter in HeLa cells overexpressing LEF1 and $\beta$-catenin. We first cloned the conserved fragments of the promoters, nucleotides $-778 /+321$ containing the $\mathrm{A}$ and 
B TSSs for human and nucleotides -920/ +388 for mouse, into a reporter plasmid with the luciferase reporter gene. We used these constructs together with LEF1 or $\beta$-catenin expression vectors to cotransfect HeLa cells (Fig. 7A). Reporter plasmids Super8xTOPflash (TOP) with eight functional LEF1 binding sites and Super8x FOPflash (FOP) with eight mutated LEF1 binding sites were used as positive and negative controls, respectively (Kaykas et al., 2004). TOP was efficiently activated by LEF1 and LEF1/ $\beta$-catenin (Fig. 7B), confirming that transcriptional activation via LEF1 was specific in HeLa cells. For the Cacnalg promoters, we found that LEF1 or $\beta$-catenin alone did not activate them; however, simultaneous LEF1 and $\beta$-catenin expression led to $\mathrm{a} \sim 3.5$-fold activation in the case of the human promoter and a $\sim 2$-fold induction in the case of the mouse promoter. These results supported the hypothesis that the $\mathrm{LEF} 1 / \beta$-catenin complex is an activator of the Cacnalg promoter.

To experimentally find the location of WREs in the Cacnalg promoter, we prepared a set of deletion mutants of the human promoter and subjected the putative LEF1 binding site to site-directed mutagenesis (Fig. 7C). The point mutations we introduced were the same as in the FOP construct. The constructs were transfected together with the LEF1 and $\beta$-catenin expression vectors. We found that mutation of the putative LEF1 binding site (WRE1) (Fig. 7D) did not change the responsiveness of the promoter to LEF1 and $\beta$-catenin, suggesting that this site was not a critical $\beta$-catenin/LEF1 responsive element in HeLa cells. Next, we analyzed deletion fragments of the promoter. Activity of the fragments $-680 /+259 \mathrm{AB},-680 /+83 \mathrm{~A}$, and $+7 /+259 \mathrm{~B}$ was increased fourfold to sixfold by the LEF $1 / \beta$-catenin complex, whereas the other two constructs, $-680 /$ $+8 \mathrm{~A}$ and $+76 /+259 \mathrm{~B}$, were less efficiently activated (approximately twofold). These weakly responsive fragments lacked nucleotides between +9 to +75 , strongly suggesting that this short fragment contains another WRE (WRE2) (Fig. 7D).

\section{Footprinting analysis revealed four LEF1 binding sites in the proximal fragment of the human and mouse Cacnalg promoter}

The results of the CACNA1G mutational analysis implied the existence of a WRE other than the in silico one predicted in the proximal region of the promoter. To map functional LEF1 binding sites in the human and mouse Cacnalg promoter, footprinting analysis was performed. We examined binding of the recombinant LEF1 protein within the proximal fragments of the promoters (Table 1). We used fragments of TOP and FOP reporters with a tandem of eight functional or nonfunctional LEF1 binding sites, respectively, as a control (Table 1). In the Cacnalg promoter, we detected four LEF1 binding sites (Fig. 8A,C). Each
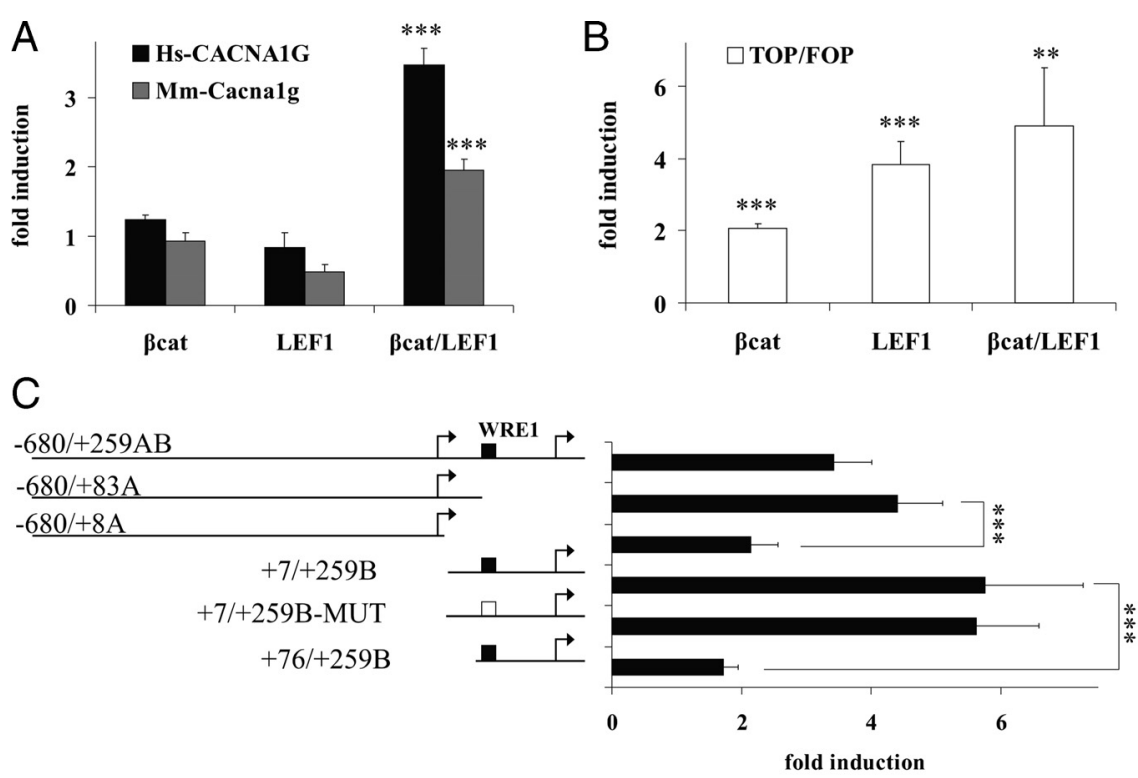

fold induction

Figure 7. Regulation of the Cacna1g promoter by LEF1 and $\beta$-catenin. $\boldsymbol{A}$, Activation of the mouse (Mm) and human (Hs) Cacna1g promoter by LEF1 and $\beta$-catenin. HeLa cells were transfected with the human and mouse promoter constructs or pTA-Luc cotransfected with $\beta$-catenin alone, LEF1 alone, and both $\beta$-catenin and LEF1 expression vectors. Additionally, Renilla

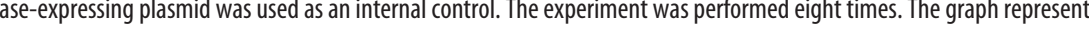

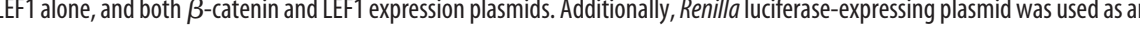
tation of the deletion and mutational analysis of the human CACNA1G promoter. The putative wild-type LEF1 binding site $(+83 /$ 9), WRE1, is represented by a black square, and the mutated version is represented by a white square. Right, Activation of the 作 as an internal control. The experiment was performed eight times. The graph represents the means for the CACNA1G promoter indicate SD. ${ }^{* * *} p<0.001$ (two-tailed Student's $t$ test). D, Graphic representation of the human CACNA1G promoter and the two possible WRES. WRE1 and WRE2 are represented by black rectangles, and the arrows mark the two alternative TSSs.

of these sites was conserved between human and mouse. We identified the exact sequences of these sites based on simultaneous $\mathrm{G}+\mathrm{A}$ chemical sequencing. One of the sites was identical with the in silico-identified WRE1 (Fig. 6). The next one overlapped with WRE2, which was identified in the luciferase assay (Fig. 7D). Upstream of these sites were situated two other sites, WRE3 and WRE4. In parallel, the fragment of the TOP, but not FOP, reporter was protected from DNase treatment by LEF1, confirming the specificity of LEF1 binding in our assay (Fig. $8 \mathrm{~B}$ ). These findings, together with the data on the promoter activation in the luciferase assay, showed that the LEF1/ $\beta$-catenin complex is able to regulate the Cacnalg promoter directly.

\section{In the thalamus, $\beta$-catenin occupies the proximal part of the Cacnalg promoter}

To establish whether $\beta$-catenin occupies the Cacnalg promoter in vivo, we used the ChIP technique. We used seven specific 

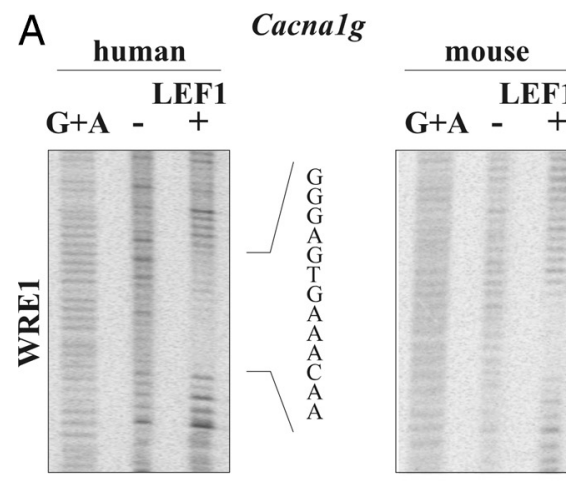

B
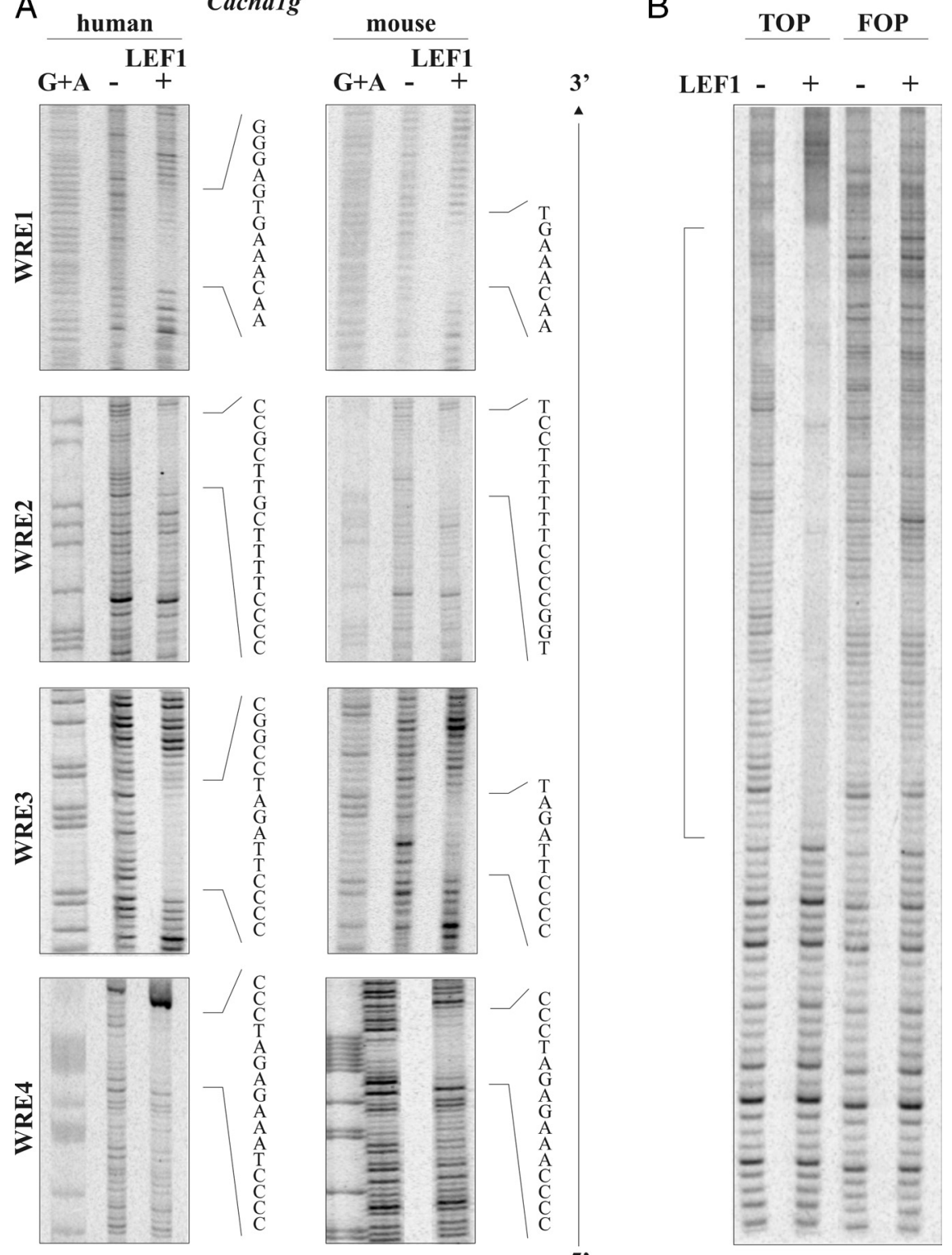

5'

C
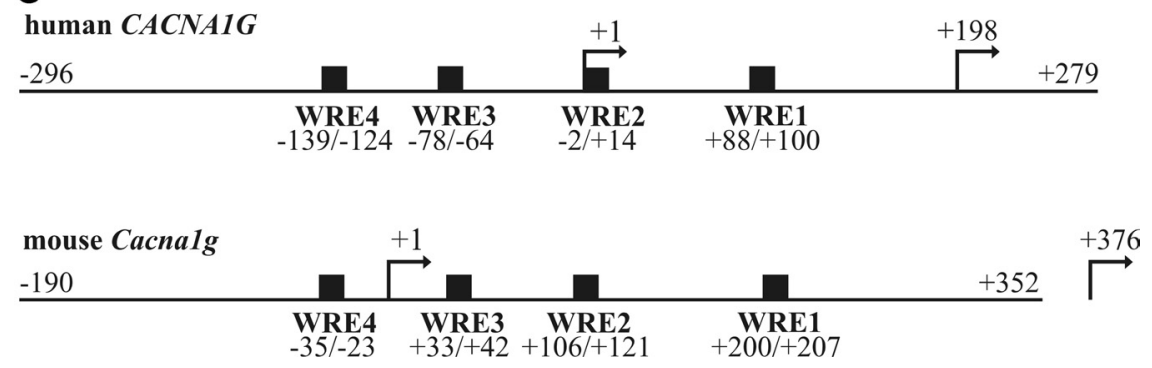

Figure 8. DNase I footprinting analysis of the human and mouse Cacna $1 g$ promoter. $A$, Binding of LEF1 to the human and mouse Cacna1g promoter. LEF1 was added to the binding reactions where indicated $(+) . G+$ A refers to the chemical sequence ladder. The LEF1-protected sites are indicated, and the exact sequences are shown. $\boldsymbol{B}$, Binding of LEF1 to TOP and FOP promoters. LEF1 was added to the binding reactions as indicated (+). The LEF1-protected fragment in the TOP promoter is shown with a bracket. $\boldsymbol{C}$, Graphic representations of the human and mouse Cacna1g promoter with the identified WREs. WREs are represented by black rectangles, and the arrows mark the two alternative TSSS. The exact locations of WRE1-4 in the human and mouse promoter are indicated. primer pairs to cover the entire conserved region $(\sim 1.1 \mathrm{~kb})$ of the mouse Cacnalg promoter (Fig. 9A).

To first determine disassembly of the chromatin structure, we assayed acetylation of the histone $\mathrm{H} 3$ within the Cacnalg promoter in the thalamus and hippocampus of the adult mouse. Fragments of the Gapdh promoter and exon (Table 2) were used as a positive and negative control, respectively. The fragments 1,2 , and 3 of the Cacnalg promoter, covering $\sim 700 \mathrm{bp}$ upstream of the first coding ATG, were strongly enriched after precipitation with anti-acetyl histone H3 (Fig. 9B). No significant difference was observed between the thalamus and the hippocampus, indicating that the chromatin structure is disassembled so that the promoter could be active in both brain areas. Despite similar histone $\mathrm{H} 3$ acetylation of the promoter, the transcription of Cacnalg was much higher in the thalamus than in the hippocampus (Fig. 5A), suggesting that activation of the promoter depends on the accessibility of specific transcription factors.

We next examined the binding of $\beta$-catenin to the Cacnalg promoter with a $\beta$-catenin-specific antibody. We used a Lef1 promoter fragment containing WRE as a positive control (Table 2), and the Gapdh promoter and exon fragments served as negative controls. The assay showed $\beta$-catenin binding within the proximal region of the Cacnalg promoter amplicons 1, 2, and 3 (containing WRE1-4 sites) and within amplicon 6 in the thalamus, but not in the hippocampus (Fig. 9C). These observations indicated that the Cacnalg promoter is a direct target of LEF1/ $\beta$-catenin in the adult thalamus.

\section{T-type calcium current is enhanced in WNT3A-treated thalamic neurons in vitro}

Finally, we investigated the consequences of $\beta$-catenin-induced Cacnalg expression in thalamic neurons at the functional level. Cacnalg encodes the Cav3.1 subunit of the T-type calcium channel. We used the patchclamp technique to check for the abundance of T-type (low-voltage-activated) currents in WNT3A-stimulated thalamic cells in vitro. The current was elicited by depolarizing pulses from a holding potential of -90 $\mathrm{mV}$ (or lower) [see steady-state inactivation experiments below and supplemental Fig. $2 A$ (available at www.jneurosci.org as supplemental material)] to $-50,-40$, and $-30 \mathrm{mV}$ (Fig. $10 \mathrm{~A}$, sample current traces elicited by depolarization to -30 $\mathrm{mV} ; B$, statistics). Under these conditions, 
A

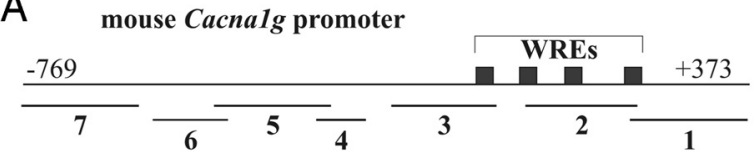

B
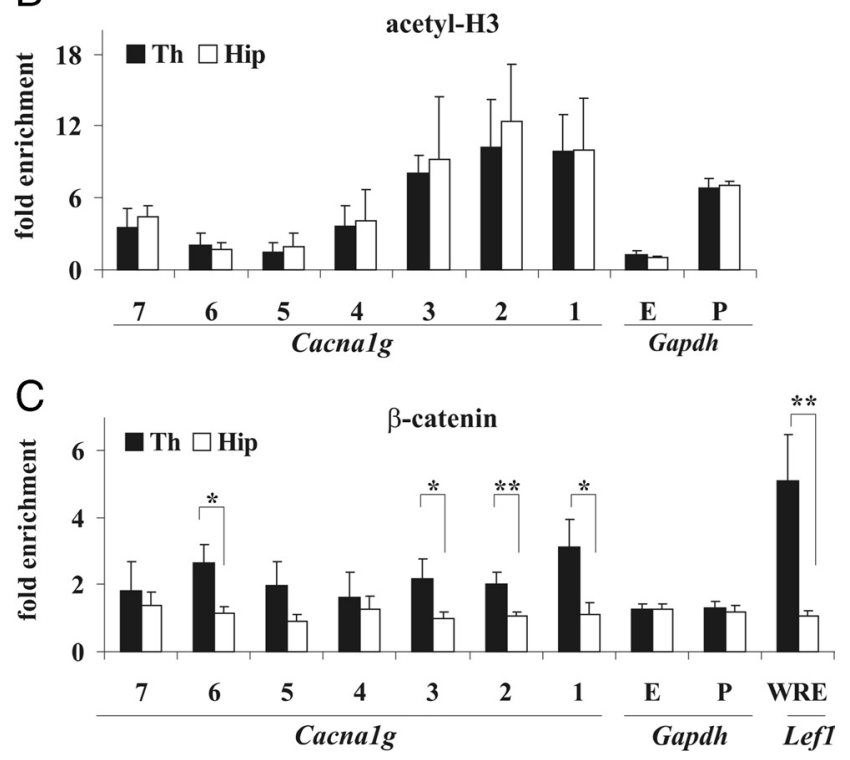

Figure 9. Analysis of the Cacnalg promoter by ChIP.A, Graphic representation of the mouse Cacna Ig promoter and amplicons used in the ChIP assay. The LEF1 binding sites identified by the footprinting analysis are represented by black squares, and the amplicons are shown as lines below the promoter. $B, C$, Real-time PCR analysis of the ChIP products. The results are expressed as fold enrichment above background ( $\lg \mathrm{G})$. The graph represents the mean of three independent experiments. Error bars indicate SD. B, Acetylated H3 histone occupancy along the Cacna1g promoter (amplicons 1-7) and the Gapdh promoter (P) and exon (E). C, $\beta$-Catenin occupancy along the Cacna1g promoter (amplicons 1-7), the Gapdh promoter (P) and exon (E), and the WRE of the Lef1 promoter. The difference between the thalamus and the hippocampus in $\beta$-catenin occupancy is statistically significant for WRE and amplicons $1,2,3$, and $6:{ }^{* *} p=$ 0.007 for WRE, ${ }^{*} p=0.016$ for amplicon $1,{ }^{* *} p=0.008$ for amplicon $2,{ }^{*} p=0.033$ for amplicon 3 , and ${ }^{*} p=0.012$ for amplicon 6 (two-tailed Student's $t$ test).

the high voltage-activated (i.e., L-type) current component is presumed to be negligible.

We performed a series of experiments identifying the observed responses as T-type currents. T-type calcium channels are known to substantially inactivate at membrane voltages close to or even more negative than the resting membrane potentials, and the standard protocol to assess steady-state inactivation was applied. A holding membrane voltage of $-90 \mathrm{mV}$ was sufficient to remove inactivation, both in controls and in WNT3A-treated neurons (Fig. 10C). Importantly, WNT3A did not affect steadystate inactivation. No significant differences in $I / I_{\max }$ values were observed at any of the holding voltages ( $I_{\max }$ was measured at a holding voltage of $-120 \mathrm{mV}$ ) between the two groups of neurons (Fig. 10C). The inactivation time course (fitted with one exponent) for controls was $23.70 \pm 3.78 \mathrm{~ms}$ (at $-30 \mathrm{mV}$; holding -90 $\mathrm{mV} ; n=12$ ), which did not differ significantly from stimulated cells $(21.71 \pm 2.57 \mathrm{~ms} ; n=22)$. Additional confirmation that the measured calcium currents were T-type came from the analysis of tail currents (supplemental Fig. $2 A, B$, available at www. jneurosci.org as supplemental material) and the observation of a crisscross pattern (supplemental Fig. 2C, available at www. jneurosci.org as supplemental material).

To determine whether stimulation with WNT3A affects the abundance of T-type calcium channels, we compared the current amplitudes measured for the respective cell groups. On average, depolarization to -40 and $-30 \mathrm{mV}$ elicited significantly larger normalized current amplitudes in the neurons treated with WNT3A (Fig. 10A, sample traces; $B$, statistics). For current amplitudes elicited by depolarization to $-50 \mathrm{mV}$, we observed a trend toward an increase in current amplitude in the group of neurons treated with WNT3A, but this difference did not reach statistical significance (Fig. $10 \mathrm{~B}$ ), possibly attributable to small amplitude values and a large scattering of data. These results indicated that activation of the $\mathrm{Wnt} / \beta$-catenin signaling pathway affects the expression of T-type calcium channels in the present model.

\section{Discussion}

In the present study we found accumulation of the LEF1 transcription factor and nuclear $\beta$-catenin in the adult brain specifically in neurons in the thalamus (dorsal thalamus). Moreover, to our knowledge, this is the first demonstration that the LEF1/ $\beta$ catenin complex activates expression of a gene specific to mature neurons. This gene, Cacnalg, encodes the Cav3.1 T-type calcium channel subunit that contributes to electric signal propagation. We also show that activation of $\mathrm{Wnt} / \beta$-catenin signaling leads to T-type current increase in thalamic cells. Previous studies on $\beta$-catenin in the adult brain have mainly focused on the role of the protein in dendritogenesis and synaptic function as a component of the cadherin adhesion complex (Yu and Malenka, 2003; Gao et al., 2007; Arikkath and Reichardt, 2008; Peng et al., 2009). The results presented here indicate the involvement of $\beta$-catenin in neuronal excitability not only by a local action at the synapse but also by regulating gene expression in thalamic neurons.

Our observation that LEF1 and $\beta$-catenin are present in cell nuclei in the thalamus essentially confirms previous reports (Lucas et al., 1999; Jones and Rubenstein, 2004; Shimogori et al., 2004). However, the present study further identifies the positive cells as neurons. The existence of nuclear $\beta$-catenin in mature neurons is unusual. Wnt/ $\beta$-catenin signaling has usually been implicated in neuronal progenitor self-renewal and neuronal lineage commitment (Chenn and Walsh, 2002; Zechner et al., 2003; Hirabayashi et al., 2004; Lie et al., 2005; Ivaniutsin et al., 2009; Kuwabara et al., 2009); therefore, this signaling has not been supposed to be particularly active in mature brain cells. Recently, $\beta$-catenin was shown to translocate into the nucleus in hippocampal neurons after tetanic stimulation or glutamate treatment (Chen et al., 2006; Abe and Takeichi, 2007; Schmeisser et al., 2009). The accumulation of $\beta$-catenin in thalamic neurons in vitro and in vivo does not require any previous stimulation. The presence of nuclear $\beta$-catenin together with LEF1, and possibly TCF7L2 (another member of the LEF1/TCF family that is expressed specifically in the thalamus) (Lee et al., 2009), implies the formation of $\beta$-catenin-containing transcription complexes in these cells and raises the possibility of specific gene expression regulation. We showed that such complexes are formed in the adult thalamus, since the known WRE of the Lef1 promoter (Filali et al., 2002; Li et al., 2006) is occupied by $\beta$-catenin in this brain region.

To address the issue of possible LEF1/ $\beta$-catenin target genes in the thalamus, we focused on a specific feature of thalamic neurons (i.e., bimodal firing generated by the dense distribution of T-type calcium channels) (Sherman, 2001; Llinás and Steriade, 2006). In situ hybridization revealed that Cacnalg encoding the T-type Cav3.1 channel subunit is expressed predominantly in thalamocortical relay neurons (Talley et al., 1999; Zhang et al., 2002), which are the major class of neuronal cells in the thalamus 


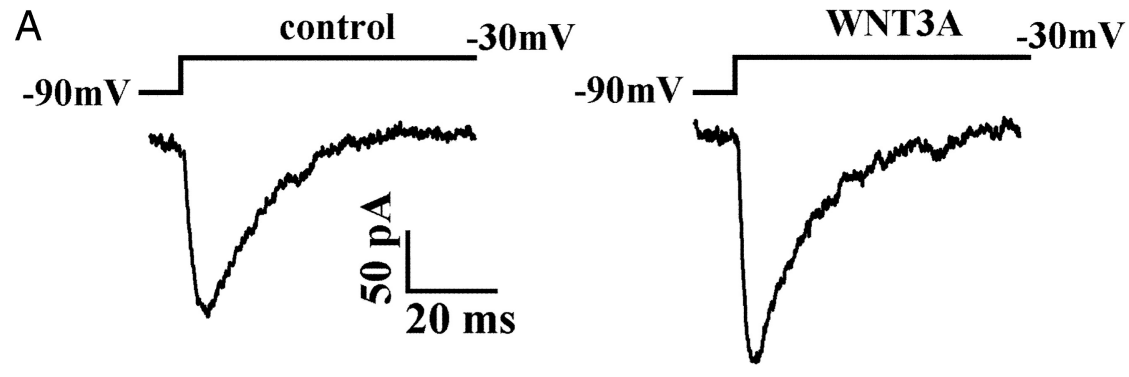

B

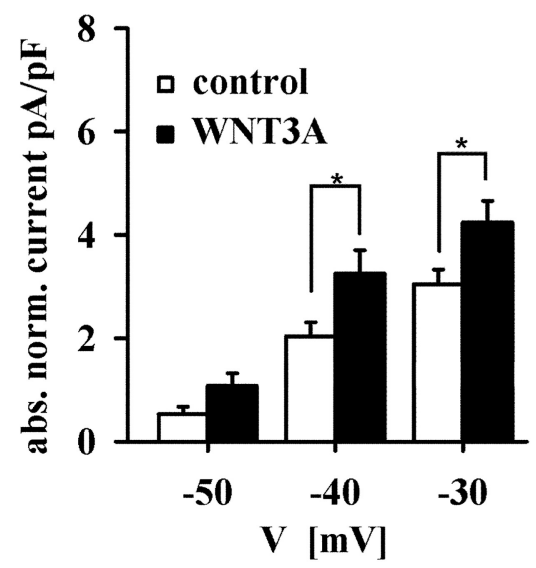

C

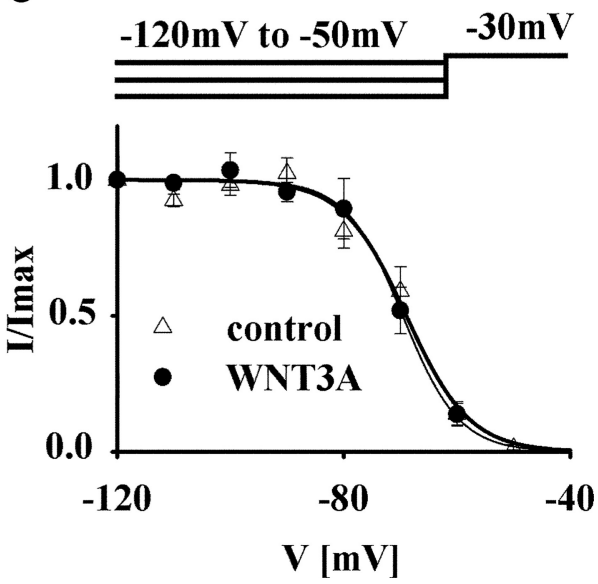

Figure 10. Enhancement of T-type calcium currents after WNT3A stimulation of thalamic cells. $\boldsymbol{A}$, Example traces of T-type calcium currents evoked for the control and WNT3A-stimulated thalamic cells. The currents, evoked by depolarization from a holding potential of -90 to $-30 \mathrm{mV}$ (insets above current traces) were measured 2-3 d after $6 \mathrm{~h}$ stimulation with WNT3A. For display purposes, the capacitive transients were manually removed from the traces, and an average of four traces (from the same cell) is presented in the figure. B, Statistics of normalized currents for the control and WNT3A-stimulated cells. The currents were evoked by depolarizing pulses from a holding voltage of $-90 \mathrm{mV}$ to potentials indicated below the bars. Error bars represent SEM. $p=0.059,{ }^{*} p=0.028$, and ${ }^{*} p=0.024$ for the depolarization to $-50,-40$, and $-30 \mathrm{mV}$, respectively (two-tailed Student's $t$ test; $n=23$ for control; $n=24$ for WNT3A-treated cells). C, Steady-state inactivation curves for the control (open circles) and WNT3A-treated neurons (filled diamonds). Currents were elicited using protocols depicted by the inset above the graph. The relationships were fitted with the Boltzmann's function (see Materials and Methods) with the following parameters (controls and WNT3A-treated neurons, respectively): $V_{\text {MID }}=-68.92$ and $-69.56 \mathrm{mV} ; V_{c}=-5.59$ and $-4.99 \mathrm{mV}$. Error bars represent SEM.

(dorsal thalamus) in rodents. Indeed, our data showed that Cacnalg mRNA levels are much higher in the thalamus than in other regions of the forebrain. This pattern perfectly coincides with LEF1 and nuclear $\beta$-catenin localization in the forebrain demonstrated here. Moreover, we showed that Cacnalg expression is increased in WNT3A-stimulated thalamic neurons in vitro and that the proximal fragment of the Cacnalg promoter, with disassembled chromatin, is occupied by $\beta$-catenin in vivo in the thalamus. In the hindbrain, however, the correlation is only partial. Cacnalg is expressed mainly in the Purkinje layer in the cerebellum and in the inferior olive (medulla oblongata) (Talley et al., 1999), whereas LEF1 and nuclear $\beta$-catenin are both present exclusively in Purkinje cells. Thus, LEF1/ $\beta$-catenin may participate in Cacnalg promoter regulation in the thalamus and presumably in the cerebellum, but not in the medulla oblongata.

Although T-type calcium channels are differentially distributed in the brain (Talley et al., 1999), and their density changes in neurons during development (Lory et al., 2006), very little is known about transcriptional regulation of T-type channel genes, including Cacna1g. The human CACNA1G promoter is hypermethylated in various tumors, which results in its repression (Toyota et al., 1999). This mechanism has not been explored in the developing brain. Instead, a switch between the two alternative promoters, from activator $\mathrm{A}$ to repressor $\mathrm{B}$, has been pro- posed to play a role in the downregulation of CACNA1G expression during neuronal differentiation (Bertolesi et al., 2003). The luciferase assay used in the present study showed that LEF/ $\beta$-catenin activates both promoters equally well. Thus, LEF/ $\beta$ catenin unlikely provides the switch. However, because one of the identified LEF1 binding sites, WRE2, lies in the proposed repressor region, LEF1 may not only simply activate the Cacnalg promoter but also change the repressor element into an activator.

We mapped several LEF1 binding elements in the proximal Cacnalg promoter. The conserved LEF1 motif, WRE1, had no impact on the regulation of the promoter in HeLa cells. Instead, deletion of the adjacent upstream fragment, containing WRE2, rendered the promoter less responsive to LEF1/ $\beta$-catenin. We suppose that WRE1 may serve as a cis-acting element in other cell types or under different conditions, as regulation of gene expression by LEF1/ $\beta$-catenin is known to be context dependent (Railo et al., 2009). We also found two other LEF1 binding sites in the Cacnalg promoter, WRE3 and WRE4, and established the exact sequence of these elements. Interestingly, the LEF1 binding elements in the Cacnalg promoter, with the exception of WRE1, are novel LEF1 motifs that do not resemble the consensus sequence. Recently, two other nonconventional LEF1/TCF binding sites were characterized (Atcha et al., 2007; Blauwkamp et al., 2008; Chang et al., 2008). The interaction of LEF1/TCF with atypical cis-elements provides a potential mechanism modulating $\mathrm{Wnt} / \beta$-catenin-dependent gene regulation (e.g., by involvement of particular coactivators in the LEF1/TCF-DNA complex) (Blauwkamp et al., 2008). We speculate that the novel LEF1 motifs in the Cacnalg promoter may be an element that affords brain-specific regulation of the promoter.

We wondered whether activation of Cacnalg expression by $\beta$-catenin had physiological effects. To elucidate this issue, we performed a set of electrophysiological experiments with thalamic cells in vitro. We found that thalamic cells exhibited increased T-type current after stimulation with WNT3A. The specificity of this current type were confirmed by several protocols, such as steady-state inactivation, inactivation kinetics, tail currents typical of T-type currents, and the occurrence of a crisscross pattern of currents (Randall and Tsien, 1997; Kuo and Yang, 2001; Perez-Reyes, 2003; Catterall et al., 2005). The enhancement in current amplitude after WNT3A application most likely results from increased expression of T-type channels because no detectable difference in the steady-state inactivation characteristics was observed, and the electrical driving force was the same when recording from the control and WNT3A-treated cells. Distinguishing between Ca3.1, Cav3.2, and Cav3.3 currents was not possible with our recordings. Although the transcripts for Cav3.2 and Cav3.3 (Cacna1H and Cacna1I, respectively) are rare in the thalamus (Talley et al., 1999; Zhang et al., 2002), they could 
still be detected in our thalamic culture. However, treatment with WNT3A exclusively elevated expression of the Cav3.1 encoding gene (Cacna1g). Therefore, we suggest that WNT3A stimulation enhances T-type calcium currents by increasing the expression of Cav3.1 channels.

Cav3.1 is likely involved in absence epilepsy in the thalamus. Transgenic mice overexpressing Cacnalg exhibited increased T-type currents in thalamic neurons and cortical spike-wave discharges associated with absence seizures (Ernst et al., 2009), whereas Cacnalg-deficient mice lacked T-type currents in the thalamus and were resistant to the generation of absence seizures (Kim et al., 2001). T-type currents are enhanced after $\beta$-catenin activation in vitro, and LEF1/ $\beta$-catenin, through the regulation of Cacnalg expression, may contribute to proper T-type currents in thalamocortical relay neurons in vivo. Consequently, impaired $\beta$-catenin regulation may be implicated in epilepsy. To examine the consequences of impaired $\beta$-catenin regulation in the thalamus, new transgenic mouse models will be required. Nominal forebrain-specific knock-out does not usually affect the thalamus, such as those based on the CamKII $\alpha$ promoter (Gould et al., 2008).

Improper Wnt signaling has been proposed to be involved in the pathogenesis of Alzheimer's disease, Parkinson's disease, schizophrenia, and mood disorders (De Ferrari and Moon, 2006; Gould et al., 2007; Mao et al., 2009; Rawal et al., 2009; Sancho et al., 2009). The function of $\beta$-catenin and LEF1/TCF transcription factors in these diseases and epilepsy is yet to be determined, but the present study opens new perspectives to the understanding and exploitation of the molecular mechanisms of these neuropathologies.

\section{References}

Abe K, Takeichi M (2007) NMDA-receptor activation induces calpainmediated beta-catenin cleavages for triggering gene expression. Neuron 53:387-397.

Arikkath J, Reichardt LF (2008) Cadherins and catenins at synapses: roles in synaptogenesis and synaptic plasticity. Trends Neurosci 31:487-494.

Atcha FA, Syed A, Wu B, Hoverter NP, Yokoyama NN, Ting JH, Munguia JE, Mangalam HJ, Marsh JL, Waterman ML (2007) A unique DNA binding domain converts T-cell factors into strong Wnt effectors. Mol Cell Biol 27:8352-8363.

Bertolesi GE, Jollimore CA, Shi C, Elbaum L, Denovan-Wright EM, Barnes S, Kelly ME (2003) Regulation of alphalG T-type calcium channel gene (CACNA1G) expression during neuronal differentiation. Eur J Neurosci 17:1802-1810.

Blauwkamp TA, Chang MV, Cadigan KM (2008) Novel TCF-binding sites specify transcriptional repression by Wnt signalling. EMBO J 27:1436-1446.

Bray N, Dubchak I, Pachter L (2003) AVID: a global alignment program. Genome Res 13:97-102.

Brembeck FH, Rosário M, Birchmeier W (2006) Balancing cell adhesion and Wnt signaling, the key role of beta-catenin. Curr Opin Genet Dev 16:51-59.

Catterall WA, Goldin AL, Waxman SG (2005) International Union of Pharmacology. XLVII. Nomenclature and structure-function relationships of voltage-gated sodium channels. Pharmacol Rev 57:397-409.

Chang MV, Chang JL, Gangopadhyay A, Shearer A, Cadigan KM (2008) Activation of wingless targets requires bipartite recognition of DNA by TCF. Curr Biol 18:1877-1881.

Chen J, Park CS, Tang SJ (2006) Activity-dependent synaptic Wnt release regulates hippocampal long term potentiation. J Biol Chem 281:11910-11916.

Chenn A, Walsh CA (2002) Regulation of cerebral cortical size by control of cell cycle exit in neural precursors. Science 297:365-369.

Clevers H (2006) Wnt/beta-catenin signaling in development and disease. Cell 127:469-480.

Coyle-Rink J, Del Valle L, Sweet T, Khalili K, Amini S (2002) Developmental expression of Wnt signaling factors in mouse brain. Cancer Biol Ther 1:640-645.

De Ferrari GV, Moon RT (2006) The ups and downs of Wnt signaling in prevalent neurological disorders. Oncogene 25:7545-7553.

Ernst WL, Zhang Y, Yoo JW, Ernst SJ, Noebels JL (2009) Genetic enhancement of thalamocortical network activity by elevating $\alpha 1$ g-mediated lowvoltage-activated calcium current induces pure absence epilepsy. J Neurosci 29:1615-1625.

Filali M, Cheng N, Abbott D, Leontiev V, Engelhardt JF (2002) Wnt-3A/ $\beta$ catenin signaling induces transcription from the LEF-1 promoter. J Biol Chem 277:33398-33410.

Frazer KA, Pachter L, Poliakov A, Rubin EM, Dubchak I (2004) VISTA: computational tools for comparative genomics. Nucleic Acids Res 32:W273-W279.

Galceran J, Miyashita-Lin EM, Devaney E, Rubenstein JL, Grosschedl R (2000) Hippocampus development and generation of dentate gyrus granule cells is regulated by LEF1. Development 127:469-482.

Gao X, Arlotta P, Macklis JD, Chen J (2007) Conditional knock-out of $\beta$-catenin in postnatal-born dentate gyrus granule neurons results in dendritic malformation. J Neurosci 27:14317-14325.

Gould TD, Einat H, O'Donnell KC, Picchini AM, Schloesser RJ, Manji HK (2007) Beta-catenin overexpression in the mouse brain phenocopies lithium-sensitive behaviors. Neuropsychopharmacology 32:2173-2183.

Gould TD, O'Donnell KC, Picchini AM, Dow ER, Chen G, Manji HK (2008) Generation and behavioral characterization of beta-catenin forebrainspecific conditional knock-out mice. Behav Brain Res 189:117-125.

Hirabayashi Y, Itoh Y, Tabata H, Nakajima K, Akiyama T, Masuyama N, Gotoh Y (2004) The Wnt/beta-catenin pathway directs neuronal differentiation of cortical neural precursor cells. Development 131:2791-2801.

Hovanes K, Li TW, Waterman ML (2000) The human LEF-1 gene contains a promoter preferentially active in lymphocytes and encodes multiple isoforms derived from alternative splicing. Nucleic Acids Res 28:1994-2003.

Hovanes K, Li TW, Munguia JE, Truong T, Milovanovic T, Lawrence Marsh J, Holcombe RF, Waterman ML (2001) Beta-catenin-sensitive isoforms of lymphoid enhancer factor-1 are selectively expressed in colon cancer. Nat Genet 28:53-57.

Hurlstone A, Clevers H (2002) T-cell factors: turn-ons and turn-offs. EMBO J 21:2303-2311.

Ivaniutsin U, Chen Y, Mason JO, Price DJ, Pratt T (2009) Adenomatous polyposis coli is required for early events in the normal growth and differentiation of the developing cerebral cortex. Neural Dev 4:3.

Jones EG, Rubenstein JL (2004) Expression of regulatory genes during differentiation of thalamic nuclei in mouse and monkey. J Comp Neurol 477:55-80.

Kaykas A, Yang-Snyder J, Héroux M, Shah KV, Bouvier M, Moon RT (2004) Mutant Frizzled 4 associated with vitreoretinopathy traps wild-type Frizzled in the endoplasmic reticulum by oligomerization. Nat Cell Biol 6:52-58.

Kim D, Song I, Keum S, Lee T, Jeong MJ, Kim SS, McEnery MW, Shin HS (2001) Lack of the burst firing of thalamocortical relay neurons and resistance to absence seizures in mice lacking alpha(1G) T-type $\mathrm{Ca}^{2+}$ channels. Neuron 31:35-45.

Kuo CC, Yang S (2001) Recovery from inactivation of T-type $\mathrm{Ca}^{2+}$ channels in rat thalamic neurons. J Neurosci 21:1884-1892.

Kuwabara T, Hsieh J, Muotri A, Yeo G, Warashina M, Lie DC, Moore L, Nakashima K, Asashima M, Gage FH (2009) Wnt-mediated activation of NeuroD1 and retro-elements during adult neurogenesis. Nat Neurosci 12:1097-1105.

Lee S, Lee CE, Elias CF, Elmquist JK (2009) Expression of the diabetesassociated gene TCF7L2 in adult mouse brain. J Comp Neurol 517:925-939.

Li TW, Ting JH, Yokoyama NN, Bernstein A, van de Wetering M, Waterman ML (2006) Wnt activation and alternative promoter repression of LEF1 in colon cancer. Mol Cell Biol 26:5284-5299.

Lie DC, Colamarino SA, Song HJ, Désiré L, Mira H, Consiglio A, Lein ES, Jessberger S, Lansford H, Dearie AR, Gage FH (2005) Wnt signalling regulates adult hippocampal neurogenesis. Nature 437:1370-1375.

Llinás RR, Steriade M (2006) Bursting of thalamic neurons and states of vigilance. J Neurophysiol 95:3297-3308.

Lory P, Bidaud I, Chemin J (2006) T-type calcium channels in differentiation and proliferation. Cell Calcium 40:135-146. 
Lucas JJ, Hernández F, Avila J (1999) Nuclear localization of beta-catenin in adult mouse thalamus correlates with low levels of GSK-3beta. Neuroreport 10:2699-2703.

Mao Y, Ge X, Frank CL, Madison JM, Koehler AN, Doud MK, Tassa C, Berry EM, Soda T, Singh KK, Biechele T, Petryshen TL, Moon RT, Haggarty SJ, Tsai LH (2009) Disrupted in schizophrenia 1 regulates neuronal progenitor proliferation via modulation of GSK3beta/beta-catenin signaling. Cell 136:1017-1031.

Maxam AM, Gilbert W (1980) Sequencing end-labeled DNA with basespecific chemical cleavages. Methods Enzymol 65:499-560.

Nawshad A, Hay ED (2003) TGFbeta3 signaling activates transcription of the LEF1 gene to induce epithelial mesenchymal transformation during mouse palate development. J Cell Biol 163:1291-1301.

Oosterwegel M, van de Wetering M, Timmerman J, Kruisbeek A, Destree O, Meijlink F, Clevers H (1993) Differential expression of the HMG box factors TCF-1 and LEF-1 during murine embryogenesis. Development 118:439-448.

Peng YR, He S, Marie H, Zeng SY, Ma J, Tan ZJ, Lee SY, Malenka RC, Yu X (2009) Coordinated changes in dendritic arborization and synaptic strength during neural circuit development. Neuron 61:71-84.

Perez-Reyes E (2003) Molecular physiology of low-voltage-activated T-type calcium channels. Physiol Rev 83:117-161.

Petropoulos K, Arseni N, Schessl C, Stadler CR, Rawat VP, Deshpande AJ, Heilmeier B, Hiddemann W, Quintanilla-Martinez L, Bohlander SK, Feuring-Buske M, Buske C (2008) A novel role for Lef-1, a central transcription mediator of Wnt signaling, in leukemogenesis. J Exp Med 205:515-522.

Railo A, Pajunen A, Itäranta P, Naillat F, Vuoristo J, Kilpeläinen P, Vainio S (2009) Genomic response to Wnt signalling is highly context-dependent-evidence from DNA microarray and chromatin immunoprecipitation screens of Wnt/TCF targets. Exp Cell Res 315:2690-2704.

Randall AD, Tsien RW (1997) Contrasting biophysical and pharmacological properties of T-type and R-type calcium channels. Neuropharmacology 36:879-893.

Rawal N, Corti O, Sacchetti P, Ardilla-Osorio H, Sehat B, Brice A, Arenas E
(2009) Parkin protects dopaminergic neurons from excessive Wnt/betacatenin signaling. Biochem Biophys Res Commun 388:473-478.

Sancho RM, Law BM, Harvey K (2009) Mutations in the LRRK2 Roc-COR tandem domain link Parkinson's disease to Wnt signalling pathways Hum Mol Genet 18:3955-3968.

Schmeisser MJ, Grabrucker AM, Bockmann J, Boeckers TM (2009) Synaptic cross talk between $N$-methyl-D-aspartate receptors and LAPSER1- $\beta$ catenin at excitatory synapses. J Biol Chem 284:29146-29157.

Sherman SM (2001) Tonic and burst firing: dual modes of thalamocortical relay. Trends Neurosci 24:122-126.

Shimogori T, VanSant J, Paik E, Grove EA (2004) Members of the Wnt, Fz, and Frp gene families expressed in postnatal mouse cerebral cortex. J Comp Neurol 473:496-510.

Talley EM, Cribbs LL, Lee JH, Daud A, Perez-Reyes E, Bayliss DA (1999) Differential distribution of three members of a gene family encoding low voltage-activated (T-type) calcium channels. J Neurosci 19:1895-1911.

Toyota M, Ho C, Ohe-Toyota M, Baylin SB, Issa JP (1999) Inactivation of CACNA1G, a T-type calcium channel gene, by aberrant methylation of its 5' CpG island in human tumors. Cancer Res 59:4535-4541.

Tutter AV, Fryer CJ, Jones KA (2001) Chromatin-specific regulation of LEF-1-beta-catenin transcription activation and inhibition in vitro. Genes Dev 15:3342-3354.

Veeman MT, Slusarski DC, Kaykas A, Louie SH, Moon RT (2003) Zebrafish prickle, a modulator of noncanonical Wnt/Fz signaling, regulates gastrulation movements. Curr Biol 13:680-685.

Yu X, Malenka RC (2003) Beta-catenin is critical for dendritic morphogenesis. Nat Neurosci 6:1169-1177.

Zechner D, Fujita Y, Hülsken J, Müller T, Walther I, Taketo MM, Crenshaw EB 3rd, Birchmeier W, Birchmeier C (2003) $\beta$-Catenin signals regulate cell growth and the balance between progenitor cell expansion and differentiation in the nervous system. Dev Biol 258:406-418.

Zhang Y, Mori M, Burgess DL, Noebels JL (2002) Mutations in highvoltage-activated calcium channel genes stimulate low-voltage-activated currents in mouse thalamic relay neurons. J Neurosci 22:6362-6371. 